\title{
Comparison of the Batch and Individual Log Study Methods for use in Determining Log Breakeven Pricing
}

\author{
Levi Eric Sisler \\ lesisler@mix.wvu.edu
}

Follow this and additional works at: https://researchrepository.wvu.edu/etd

Part of the Other Forestry and Forest Sciences Commons, and the Wood Science and Pulp, Paper Technology Commons

\section{Recommended Citation}

Sisler, Levi Eric, "Comparison of the Batch and Individual Log Study Methods for use in Determining Log Breakeven Pricing" (2020). Graduate Theses, Dissertations, and Problem Reports. 7967.

https://researchrepository.wvu.edu/etd/7967

This Thesis is protected by copyright and/or related rights. It has been brought to you by the The Research Repository @ WVU with permission from the rights-holder(s). You are free to use this Thesis in any way that is permitted by the copyright and related rights legislation that applies to your use. For other uses you must obtain permission from the rights-holder(s) directly, unless additional rights are indicated by a Creative Commons license in the record and/ or on the work itself. This Thesis has been accepted for inclusion in WVU Graduate Theses, Dissertations, and Problem Reports collection by an authorized administrator of The Research Repository @ WVU. For more information, please contact researchrepository@mail.wvu.edu. 


\title{
Comparison of the Batch and Individual Log Study Methods for use in Determining Log Breakeven Pricing
}

Levi E. Sisler

West Virginia University Division of Forestry \& Natural Resources,

Appalachian Hardwood Center

\begin{abstract}
Thesis submitted to the Davis College of Agriculture, Natural Resources, and Design at West Virginia University

in partial fulfillment of the requirements for the degree of
\end{abstract}

Master of Sciences
in
Forestry

Joseph McNeel, PhD, Committee Chairperson

Curt Hassler, PhD

Jan Wiedenbeck, PhD

Division of Forestry and Natural Resources

Morgantown, West Virginia

2020

Keywords: Log Grading, Sawmill Study, Individual Log Study

Copyright 2020 Levi Sisler 


\begin{abstract}
Developing an Empirical Basis for a Hardwood Log Grading System

Levi E. Sisler
\end{abstract}

Understanding log yields and overrun is critical to a profitable sawmill operation. Lumber yield and overrun data can be gathered through one of two types of sawmill studies: batch studies or individual log studies. Little to no research has previously been conducted to determine if one method provides more reliable results than the other method. For this effort, 16 batch studies were conducted. Individual log studies were also conducted on the same logs, allowing a direct comparison of the results from both study types. A breakeven analysis was conducted for each study type, which determined the amount of variability in breakeven prices generated from the two types of sawmill studies. Results show that batch compositions were quite variable, leading to unreliable breakeven pricing results. The individual log study method provided more reliable lumber yield and overrun results, leading to more reliable breakeven pricing results. 


\section{Table of Contents}

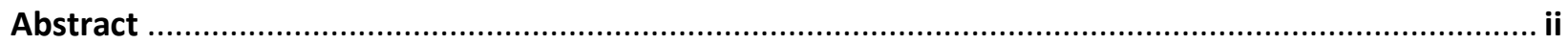

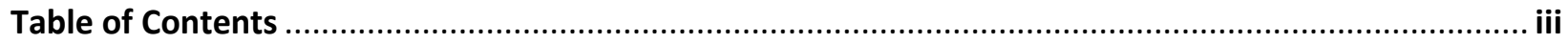

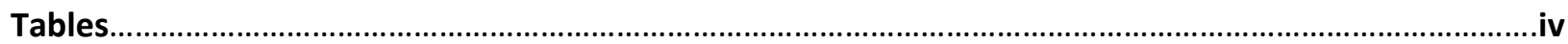

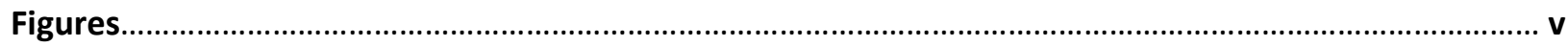

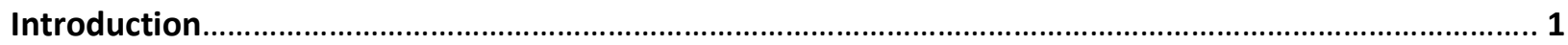

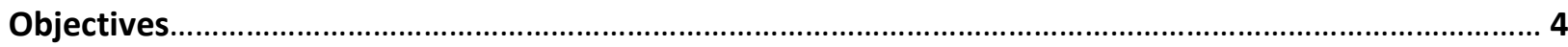

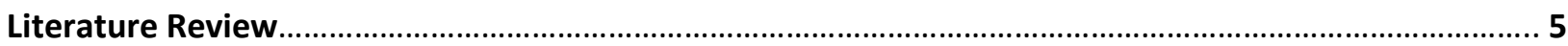

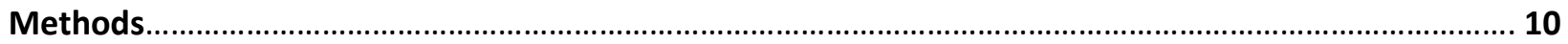

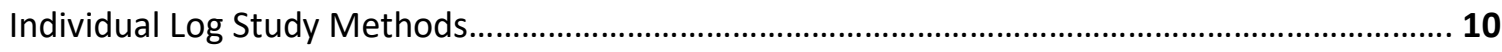

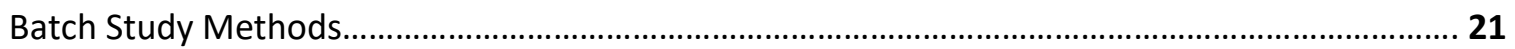

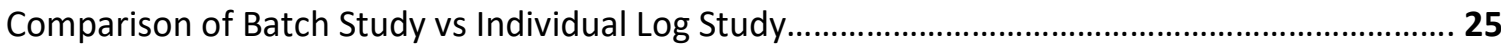

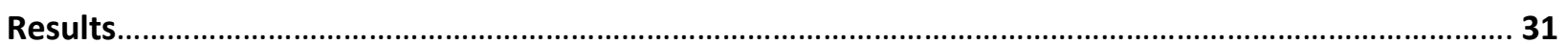

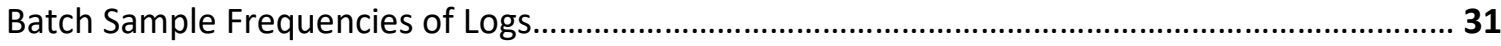

Comparison of Batch Composition with Individual Log Approach..................................................34

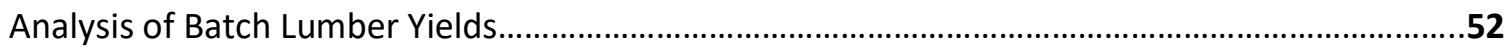

Comparison of Lumber Grade Yields between the Batch and Individual Log Methods..................57

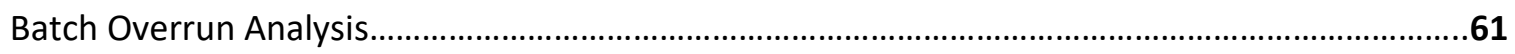

Comparison of Overrun between the Batch and Individual Log Methods......................................63

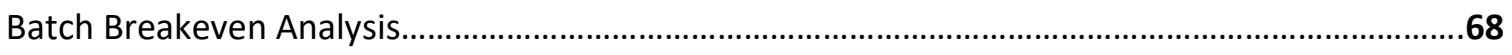

Batch Results using AHC Log Grading and Scaling.......................................................................

Individual Log Breakeven Analysis, AHMI/AHC Method....................................................................74

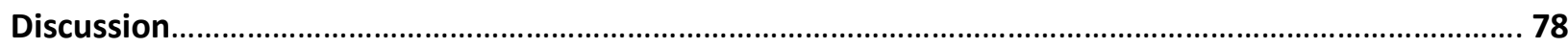

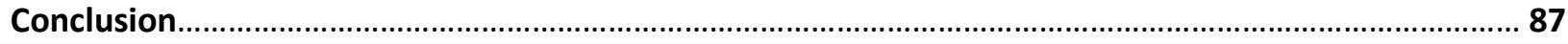

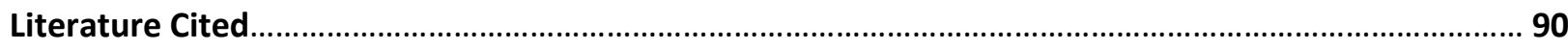

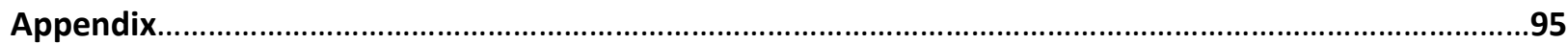




\section{Tables}

Table 1: Summary of the Kappa Agreement Statistic for all 16 Batches in the Study...51

Table 2: One Face and Better Lumber Yields for the Batch and Individual Log

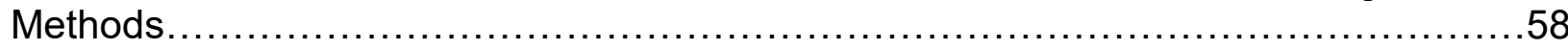

Table 3: One Common Lumber Yields for the Batch and Individual Log Methods.......59

Table 4: Two Common and Lower and Cant Lumber Yields for the Batch and Individual

Log Methods.

Table 5: Differences in Overrun between the Batch Mill Study and Individual Log Mill

Study Methods using the Wilcoxon Nonparametric Test.

Table 6: Differences in Overrun between the Batch Mill Study and Individual Log Mill Study Methods using Student's t-test for Normally Distributed Data.....................66

Table 7: Differences in Overrun between the Batch Mill Study and Correctly Graded Logs According to the Individual Log Study Methods using the Wilcoxon nonparametric test. 66

Table 8: Differences in Overrun between the Batch Mill Study and Correctly Graded Logs According to the Individual Log Study Methods using Student's t-test for Normally

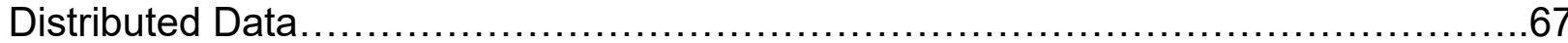

Table 9: Lumber Grade Yields and Overrun for Red Oak Batch Studies.................68

Table 10: Lumber Grade Yields and Overrun for Yellow-poplar Batch Studies............69

Table 11: Lumber Grade Yields and Overrun for Soft Maple Batch Studies..............70

Table 12: Lumber Grade Yields and Overrun for Soft Maple Batch Studies..............70

Table 13: Red Oak Batch Study Results using AHC Log Scaling Results................71

Table 14: Yellow-poplar Batch Study Results using AHC Log Scaling Results............71

Table 15: Soft Maple Batch Study Results using AHC Log Scaling Results..............72

Table 16: Cherry Batch Study Results using AHC Log Scaling Results...................72

Table 17: Lumber Grade Yields and Overrun for Revised Red Oak Batches.............73

Table 18: Lumber Grade Yields and Overrun for Revised Yellow-poplar Batches........73

Table 19: Lumber Grade Yields and Overrun for Revised Soft Maple Batches............74

Table 20: Lumber Grade Yields and Overrun for Revised Cherry Batches................74

Table 21: The Number of Logs from the AHMl'AHC Method of Individual Log Analysis in each Cell of the Scaling Diameter/Clear Face Matrix, as defined by the Cooperating Mill's Grading and Scaling Protocols ................................................... 75

Table 22: Lumber Grade Yields and Overrun for the Individual Log Analysis.............76 


\section{Figures}

Figure 1: Illustration of Sweep in a Hardwood Log..................................12

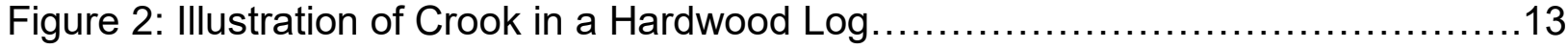

Figure 3: Illustration of an Interior Defect in a Hardwood Log............................13

Figure 4: Illustration of a Sector Defect in a Hardwood Log...........................14

Figure 5: Illustration of Shake in a Hardwood Log..................................... 15

Figure 6: Illustration of a Split in a Hardwood Log.......................................16

Figure 7: Obtaining Four, Equally Sized Grading Faces..............................17

Figure 8: Log Grading Specifications of the Participating Sawmill.......................23

Figure 9: Interpretation of the Kappa Agreement Statistic ............................26

Figure 10: Comparison of Log Grade Distributions of the Individual Log and Batch Study Methods for the Grade 2 Small Diameter Red Oak Batch............................. 35

Figure 11: Comparison of Log Grade Distributions of the Individual Log and Batch Study Methods for the Grade 2 Large Diameter Red Oak Batch..............................36

Figure 12: Comparison of Log Grade Distributions of the Individual Log and Batch Study Methods for the Grade 1 Small Diameter Red Oak Batch..............................37

Figure 13: Comparison of Log Grade Distributions of the Individual Log and Batch Study Methods for the Grade 1 Large Diameter Red Oak Batch..............................38

Figure 14: Comparison of Log Grade Distributions of the Individual Log and Batch Study Methods for the Prime Grade Red Oak Batch........................................

Figure 15: Comparison of Log Grade Distributions of the Individual Log and Batch Study Methods for the Prime Grade Yellow-poplar Batch. .40

Figure 16: Comparison of Log Grade Distributions of the Individual Log and Batch Study Methods for the November Grade 1 Small Diameter Yellow-poplar Batch.................41

Figure 17: Comparison of Log Grade Distributions of the Individual Log and Batch Study Methods for the January Grade 1 Small Diameter Yellow-poplar Batch...................42

Figure 18: Comparison of Log Grade Distributions of the Individual Log and Batch Study Methods for the Grade 1 Large Diameter Yellow-poplar Batch

Figure 19: Comparison of Log Grade Distributions of the Individual Log and Batch Study Methods for the Grade 2 Small Diameter Yellow-poplar Batch.

Figure 20: Comparison of Log Grade Distributions of the Individual Log and Batch Study Methods for the Grade 2 Large Diameter Yellow-poplar Batch........................45

Figure 21: Comparison of Log Grade Distributions of the Individual Log and Batch Study Methods for the Prime Grade Soft Maple Batch. 
Figure 22: Comparison of Log Grade Distributions of the Individual Log and Batch Study Methods for the Grade 1 Small Diameter Soft Maple Batch...........................47

Figure 23: Comparison of Log Grade Distributions of the Individual Log and Batch Study Methods for the Grade 1 Large Diameter Soft Maple Batch...........................48

Figure 24: Comparison of Log Grade Distributions of the Individual Log and Batch Study Methods for the Grade 1 Small Diameter Cherry Batch.................................49

Figure 25: Comparison of Log Grade Distributions of the Individual Log and Batch Study Methods for the Grade 2 Small Diameter Cherry Batch...............................50

Figure 26: Breakeven Prices for the Red Oak Batches..............................77

Figure 27: Breakeven Prices by Scaling Diameter and Clear Faces based on the AHMI/AHC Method of Individual Log Studies............................................77 


\section{INTRODUCTION}

The lack of a universally accepted log grading system has always affected the hardwood lumber industry. The USDA Forest Service recognized this issue and worked to develop a hardwood log grading system that would address the problem (Wollin 1949), but the industry found this system to be difficult and time consuming, significantly reducing utility in a production environment (Hassler et al. 2019).

Hardwood sawmills have addressed this issue by creating their own "streamlined" log grading systems. Most of these proprietary grading systems involve determination of the small-end diameter and counting the number of clear faces on the log. When each mill has their own grading system it is difficult to compare log pricing between mills, since each mill's log grades are rarely equivalent. The lack of comparable log grades can lead to potential issues between log buyer and seller.

A new system developed by the West Virginia University Appalachian Hardwood Center (AHC) and adopted by Appalachian Hardwood Manufacturers, Inc. (AHMI) in 2019, was created to serve as a regional and national standard for hardwood log grading (Appalachian Hardwood Manufacturers Inc. 2019). This new log grading system is a "clear-face" grading system, similar to those in use at most hardwood mills today.

The grading system is built on empirical data gathered from mill studies conducted throughout the Appalachian region and its accuracy in predicting appropriate log grades relies heavily on previously collected log yield data provided through sawmill studies. Sawmill studies are the primary way to predict the range and quality of the lumber-based products created from a log with certain measurable characteristics. The 
data gathered from an individual log mill study can be consolidated to see exactly what products were sawn from a given log.

This newly developed grading system can also be used to generate break-even prices of individual logs, based on four key pieces of information. Specifically, the information needed to accurately develop a break-even price per thousand board feet for a specific log must include accurate estimates of lumber yields by grade from the log, sawing costs per MBF of recovered lumber at the processing mill, overrun/underrun values for the log in question, and product pricing by lumber grade.

Lumber grade yields can be determined for each log and can be combined with lumber pricing information to determine the value of the lumber sawn from a given log. This forms the basis for conducting a log yield study- to capture the lumber volumes and values recovered for a specific log.

Sawing costs are typically expressed in "\$ per MBF" by many mills and are typically estimated using empirically based costs for a specific mill. Additionally, sawing times per log can be measured in a sawmill study, which can help mill management more accurately determine log sawing costs.

Overrun or underrun must be calculated for each log. Overrun is defined as lumber output being greater than log scale, while underrun can be defined as a situation where log scale is greater than lumber output (Avery 2002). Two figures are needed to calculate overrun or underrun, log scale and lumber tally. To obtain log scale, log length and small-end diameter inside the bark (DIB) is needed. 
Log yield studies allow mills to better understand the products they manufacture from an individual log, as well as the potential profit from those products and consequently, the purchased log. This accurate log yield data is vital for mill profitability during periods when lumber prices are weak or log supplies are tight which, individually or in combination, lead to smaller profit margins. With accurate estimates of these four components, mill management is able to predict break-even prices and set the maximum price to pay for purchased logs to ensure that raw material costs for the mill are reasonable and can sustain a desired level of profitability.

Log yield data from sawmill-based log yield studies is crucial for a sawmill's ability to accurately price the logs they purchase. Mills provide log specification sheets to their suppliers to detail how logs are to be manufactured in the field and define the price per MBF that the company is paying by grade and species.

Results obtained from sawmill-based log yield studies can be used to accurately value a log of a given species and grade. This eliminates the guesswork that typically occurs when mills are assigning prices to the logs they purchase. Without accurate log yield data, there is no way to price logs that will ensure their acquisition is profitable prior to being processed through the sawmill.

There are two primary methods available for conducting mill studies, the batch and the individual log study methods. The method employed in the AHC/AHMI log grading system is the individual log study, while the other method used by most sawmills is the batch mill study. The batch study tends to be used because data collection is simplified using this approach. 
In an individual log study, lumber produced from an individual log is tracked from primary breakdown at the headrig, through all the processing steps in the mill, and is finally tallied when all the produced lumber is measured, graded, and stacked on the green chain. Each log is identified by a number, and each board or cant produced from that $\log$ is also identified with the log number from which it was produced to enable tracking through the processing steps.

With the batch mill study, log data is gathered prior to entering the mill and the lumber yield from all the processed logs in the batch are recorded after the batch has been processed. As such, it is not possible to determine the volume and grade of lumber that was manufactured from each log. A batch mill study is much easier for most mills to conduct; however, there is no way to match the collected data to individual logs. Mixing grades and log sizes within a batch produces results with limited analytical value.

\section{OBJECTIVES}

There are four objectives to this study. They include;

1. Document how data from an individual log study can be utilized to accurately value a log,

2. Document the procedures associated with conducting an individual log study and those used for conducting a batch study of logs run through a mill,

3. Compare results of a batch mill study to an individual log study conducted on the same logs, to include yield data and break-even price analysis and 
4. Illustrate the utility of using an individual mill study relative to the batch mill study approach.

\section{LITERATURE REVIEW}

The importance and utility of log yield data has been recognized since the early development of hardwood log grading systems. Benson and Wollin (1938) suggested using lumber yield data as the basis of a future hardwood log grading system. Their work focused on defining the relationship between log defects and lumber grade. To achieve this, logs were scaled, and the defects were diagrammed. Logs were then tracked individually through the mill and lumber data was recorded.

Herrick (1946), in conjunction with the Purdue University Agricultural Experiment Station, worked to better understand lumber grade yields and overrun/underrun in Indiana hardwood sawlogs. Their study methods were very similar to Benson and Wollin (1938), where logs were tracked individually through the sawmills. Sawing time per log was also recorded in this study to incorporate sawing costs into stumpage value calculations.

In 1949, A.C. Wollin and C.L. Vaughan presented mill study results from approximately 11,000 logs sawn across the eastern US. This lumber yield data is presented in a series of tables organized by species and log grade. The authors state that three grades of logs are sufficient for an accurate evaluation of logs, therefore log yield data is displayed for each species with three log grades in each species group. An 
individual log study approach, similar to that described by Benson and Wollin (1938), was used to obtain the data. For each log species and grade, tables provided lumber grade yields in percentages for each grade, along with overrun percentages using the Scribner Decimal C log rule. This publication was later revised to update and adjust some of the original lumber yield data (Vaughan et al., 1966).

Calvert (1956) detailed log grading research efforts in progress by the USDA Forest Service and how a similar system would be useful in the Canadian hardwood industry. At the time, the Forest Products Laboratories of Canada was conducting log yield studies to determine if the USDA Forest Service log grading system was useful when dealing with Canadian hardwood timber species. The Forest Products Laboratories of Canada used an individual log study where each log was scaled with defects diagrammed and then processed and tracked through the sawmill. This publication did not present any results from the study, however.

Schroeder and Hanks (1967) published the results from a log yield study on northern red oak factory-grade logs. A total of 556 sawlogs from four different mills in Virginia and West Virginia was included in the study. Lumber yields were recorded for each log after the lumber had air-dried to 20 percent moisture content.

The next year, Schroeder (1968) built on his previous work and published log yields for sub-factory grade red oak logs. Factory grade logs are those logs that yield NHLA grade lumber, and this lumber is intended to be further processed to produce defect-free pieces intended for use in furniture and flooring. Sub-factory grade logs are those logs that are not suitable to produce grade lumber. These logs are usually processed into ties, timbers, or pallet components (Rast 1973). The log yield study 
occurred in Illinois and included 235 logs. Both green and dry lumber grades were recorded, but only dry lumber grade yields were included in the publication. Schroeder provided an example of how a mill operator could use this yield data, combined with lumber prices and production costs, to determine the break-even cost on an individual log basis.

Hanks (1973) also published lumber yield data for sub-factory (low grade, low value) hardwood sawlogs and considered most commercial hardwood species in the study. This work could be considered a continuation of Schroeder (1968), which provided lumber yield information for sub-factory Red Oak sawlogs. There were over 600 logs of varying species of the sub-factory grade sawn for inclusion in this publication. Green lumber grade yield percentages by diameter were included for ten hardwood species.

The last significant lumber yield study from the Forest Service was published by Hanks et al. (1980). Additional yield data was combined with the previously published yield information presented in Vaughan et al. (1966). Dry lumber grade yields are presented for twelve species, along with green lumber grade yields for an additional six species. The authors also detail how the lumber grade yields can be utilized, with current lumber prices by grade and overrun figures, to determine the value of lumber sawn from an individual log.

The state of Vermont conducted 110 sawmill studies from 1973 to 1983 as part of their sawmill improvement program (Gove 1984). Over 21,000 hardwood and softwood logs were analyzed as a part of this program. The program utilized individual log studies to obtain yield data. Sawing time at the headrig for each log was recorded to 
allow sawing cost estimates to be developed, so that these cost estimates could be incorporated into overall log value. Other data gathered from the mill studies included chip production per MBF by species, downtime, and sawing thickness variation. Differences in overrun, sawing costs, and lumber recovery factor (LRF) between band mills and circular mills were also detailed in the paper. Steele (1984) defined lumber recovery factor as the amount of board footage recovered from a given cubic volume of logs.

Burry et al. (1977) detailed study efforts in New York focused on improved lumber recovery in hardwood sawmills. A total of 20 mill studies, totaling 4,316 logs, were conducted using the individual log study method. Sawing times and lumber thickness variations were measured at each mill. The presented lumber yield data is limited, with the percentage of 1 common and better lumber produced from each mill being the only lumber yield data provided. Differences in lumber recovery, overrun, hourly production, and sawing thickness variation between circular and band sawmills were also presented in the paper. Finally, many recommendations were made that could lead to improvements in lumber yield and grade recovery with both circular and band sawmills.

Govett et al. (2006) details the differences between individual log studies and batch mill studies, as well as differences in the utility of data obtained through these studies. The authors cite several possible causes of variation in log yield results between mills, such as different equipment configurations and processing strategies in the mills. The authors assert that the variability between sawmills is the primary reason that log yield studies should be conducted on an individual sawmill basis. 
The authors further define an individual log study as having the ability to trace lumber data back to each log separately. This means that each log is numbered, and each board produced from that log is labeled with the same number. They state that the main advantage of an individual log study is that it provides log specific data such as overrun, lumber grade distributions and break-even cost. This study method is more detailed and requires more labor than does a batch mill study. This detail can lead to slowed production in larger sawmills, especially when the sample size is large.

A batch mill study was defined as a data collection process where a group of study logs are processed together, with the data gathered for the group, rather than producing any specific individual log data. A batch mill study is somewhat more simplified and requires less manpower than an individual log study, making the batch mill study easier for sawmills to conduct in an inexpensive manner without additional assistance. The authors further state that a batch is typically defined by species and log grade. Data such as overrun and lumber volumes by grade can easily be determined for the batch. The authors stress that in this study method, the range of diameters and log lengths included in the study should be relatively similar to the overall mix of logs brought to the mill. Otherwise, certain diameters or lengths will be overrepresented in the sample, thus affecting the accuracy and value of the data. If more large logs are included in the sample than is typical in the normal log mix, overrun may be quite different than should be expected from the normal mix.

Mayer and Wiedenbeck (2005) describe the process and advantages of continuous sawmill studies. This study method consists of gathering log yield data whenever conditions allow, such as when the mill is fully staffed. The results will provide 
yield data and profitability across a wide range of conditions. An individual log study approach is suggested for use in the continuous mill study. The authors also detail the disadvantages of batch mill studies. They note that batch study data may not provide accurate lumber yield data or profitability information for the range of operating conditions or log characteristics that a hardwood sawmill would experience. Of particular interest, the authors state that "In short, the information from a batch mill study does not provide quantitative results with the accuracy necessary to make critical decisions affecting mill operations ${ }^{1 "}$.

\section{METHODS}

In order to conduct a comparison of batch versus individual log studies, it was necessary to engage a hardwood sawmill partner that had interest in using this approach. For this study, a hardwood sawmill in Pennsylvania was interested in cooperating on a project focused on comparing batch and individual log analyses. That mill traditionally conducted batch studies to collect log yields and expressed a keen interest in comparing their results to those from an individual log study approach.

\section{Individual Log Study Methods}

\section{Log Scaling}

The first step of the mill study process is to scale and grade the logs included in the study. Each log was numbered, on both ends of the log, so that scaling and grade

\footnotetext{
${ }^{1}$ Page 2
} 
data could be matched to each log. In the log scaling process, the log characteristics measured include the small-end diameter, log length, and trim allowance.

The position of the log in the tree was recorded. Logs were classified as either butts or uppers. Diameter inside the bark (DIB) was measured on the small end of the log by measuring twice, once in the shortest direction, and then 90 degrees to the shortest direction, and then averaged. If the fraction of the average was greater than 0.5 it was rounded up, otherwise it was rounded down (Appalachian Hardwood Manufacturers Inc, 2019). This average provided the scaling diameter of the log. Log length was measured to the nearest even foot and the excess length beyond the even foot was the trim allowance for the purposes of this study.

Scaling defects were identified, measured, and recorded for each log. Defects included sweep, crook, interior defects and sector defects. Also, each end was observed for defects such as spider heart, splits, shake, and interior defects such as heart rot/decay. A rule-of-thumb scaling deduction was utilized to adjust log scale due to scaling defects. These rules-of-thumb either deduct diameter or log length to reduce the scaling volume of the log to account for scaling defects. A description and illustration of each of these defects is included below, along with the rules-of-thumb to adjust log scale for each defect type. All rules-of-thumb used in this study were adopted from the AHMI log grading system (Appalachian Hardwood Manufacturers Inc., 2019).

Sweep is measured as the amount of deflection, in inches, outside the normal scaling cylinder. Figure 1 illustrates a log containing sweep. Sweep is measured by the amount of departure the log has from a straight line between the two ends of the log. The point having the maximum amount of sweep is measured and used to determine 
scaling deductions. The rules-of-thumb allow for either a length or diameter deduction to be taken. The rule for length deduction is $\frac{\text { Gross Sweep in Inches }}{3}$ with the deduction taken in feet of length. The rule for diameter deduction is $\frac{\text { Gross Sweep in Inches }}{4}$ with the deduction taken in inches of diameter at the small end of the log. In both the length and diameter formulas, only the whole number is utilized to make the scaling deduction. If gross sweep is greater than or equal to $1 / 2$ of the scaling diameter, the log is culled.

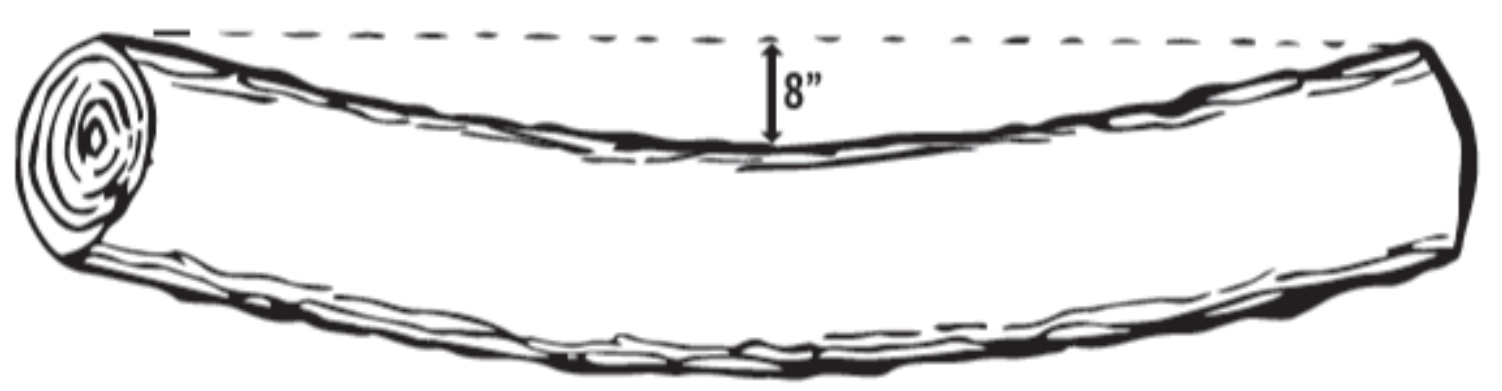

Figure 1. Illustration of Sweep in a Hardwood Log. (Appalachian Hardwood Manufacturers Inc., 2019)

Crook is a scaling defect where a portion of the log abruptly departs from a straight line. Two measurements are needed to determine crook. The first measurement is the length of the crook measured in feet, and the second is the amount of crook measured in inches. Figure 2 provides an example of a log that contains crook. Only a length deduction rule is available for crook. The formula is $\frac{\text { Crook length in feet }}{3}$ and the deduction is made in feet of length. Again, any fraction from the formula is ignored. If the length of the crook is greater than or equal to $1 / 2$ the log length, the crook is dealt with as sweep. 


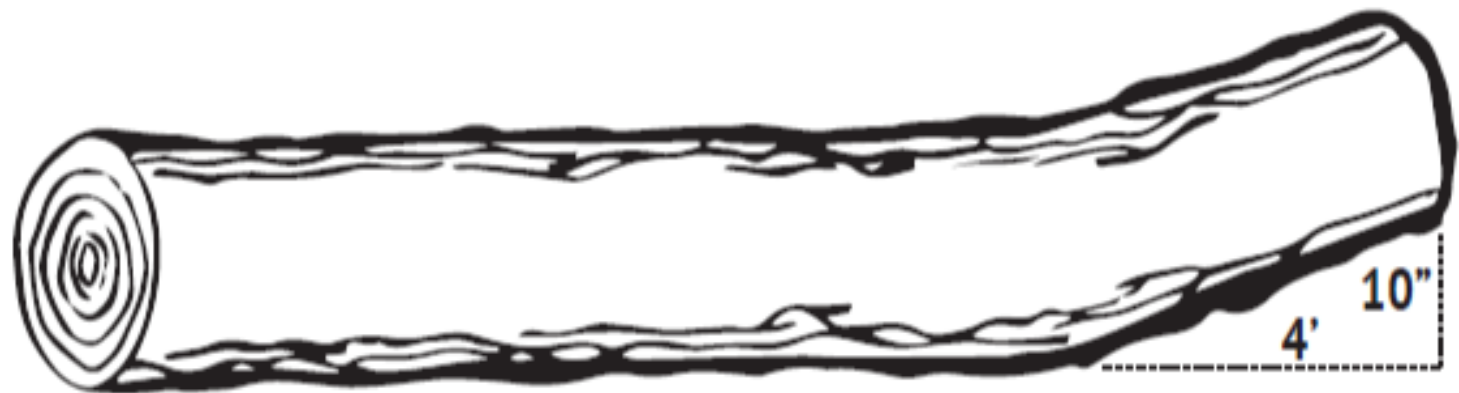

Figure 2. Illustration of Crook in a Hardwood Log. (Appalachian Hardwood Manufacturers Inc., 2019)

Interior defects are any defect that occurs within the log, such as holes or rot. Two measures, the height and the width in inches, are needed to determine the size of the interior defect. These measurements are averaged and called the defect diameter. The rule-of-thumb for accounting for interior defects is a diameter reduction based on the formula $\frac{\text { Defect Diameter }}{3}$. Only the whole number is used to make the scaling deduction. Figure 3 illustrates a log containing an interior defect and how the needed measurements are taken.

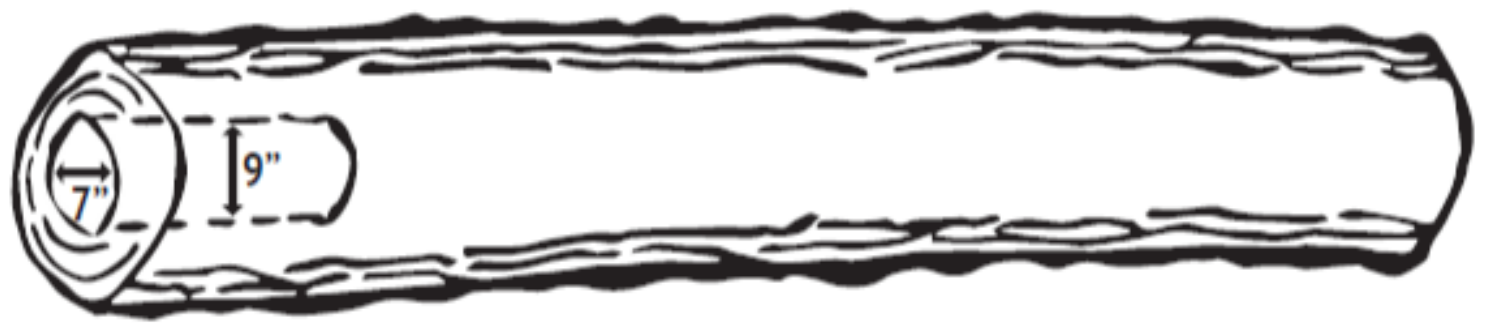

Figure 3. Illustration of an Interior Defect in a Hardwood Log. (Appalachian Hardwood Manufacturers Inc., 2019)

Sector defects are accounted for through a length deduction. Figure 4 provides an illustration of a sector defect. The length of the sector defect is measured. The scaler 
must estimate the portion of log circumference, as a percentage, that contains the sector defect. The rule-of-thumb for sector defects is $\frac{\text { Sector Cirumference }(\%)}{100} \times$

Sector Length. Any fraction greater than or equal to 0.5 is rounded up to the nearest foot. Forn the log illustrated in Figure 4, the scaling deduction would be calculated as $\frac{25}{100} \times 3$, which is 0.75 . This would round up to be a 1 -foot length deduction.

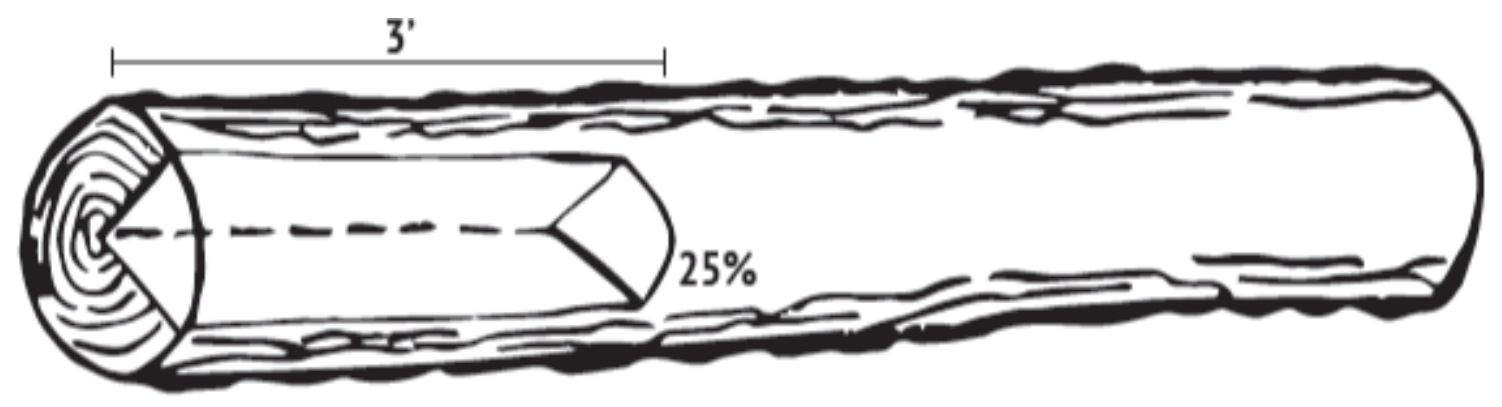

Figure 4. Illustration of a Sector Defect in a Hardwood Log. (Appalachian Hardwood Manufacturers Inc., 2019)

Shake is a separation of growth rings in a log. It is visible on the end of a log. Figure 5 provides an example of a log containing shake. The severity of the shake depends on the distance from the pith and the amount of log circumference it covers. A ring shake that is less than or equal to four inches from the pith and is less than $50 \%$ of the circumference can be ignored. A ring shake that is less than or equal to four inches from the pith and more than $50 \%$ of the circumference at that point is treated as an interior defect. Any shake that is more than four inches from the pith is treated as an interior defect, and the rule-of-thumb for an interior defect is used to make the scaling deduction. 
Figure 5 illustrates ring shake in a log that is 18 inches diameter inside bark at the small end, with a length of 16 feet. There is ring shake on the small end of the log located eight inches from the pith, for $100 \%$ of the log circumference. Using the rules-ofthumb, a two-inch diameter deduction should be taken on this log.
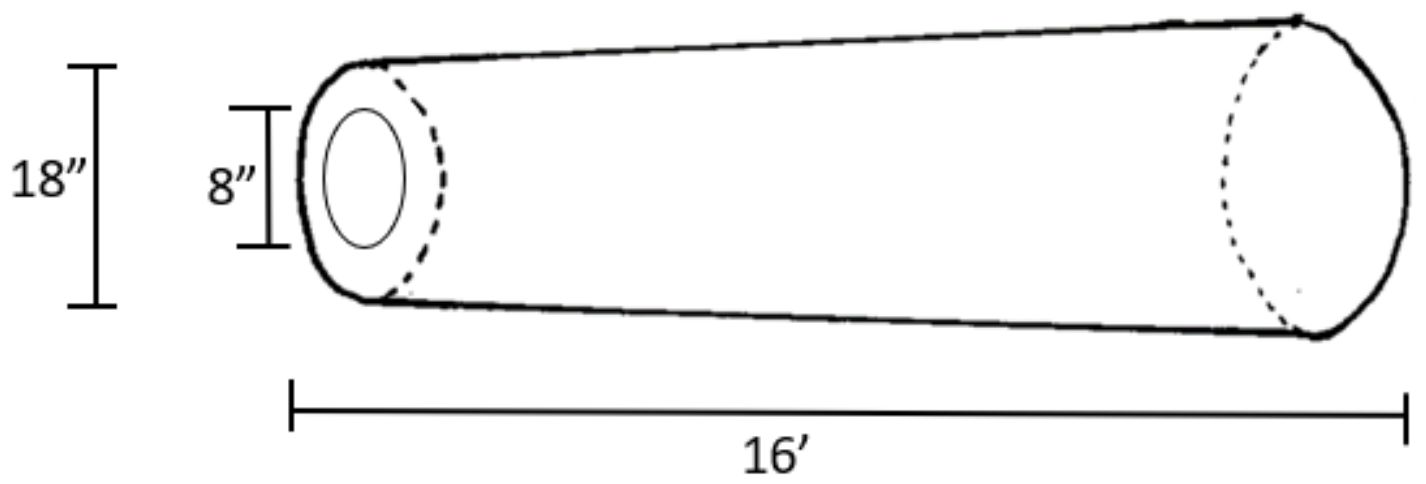

Figure 5. Illustration of Shake in a Hardwood Log. (Graves, 1986)

Splits are a scaling defect caused by a separation of the wood. Figure 6 provides an illustration of a log containing a split. Log length is reduced to account for this type of scaling defect. The rule-of-thumb for splits is to determine how far the split extends into the log and deduct length in two-foot increments, or 1-foot increments at the discretion of the mill. Based on the rules-of-thumb a two-foot length deduction should be taken on the log illustrated in Figure 6. 


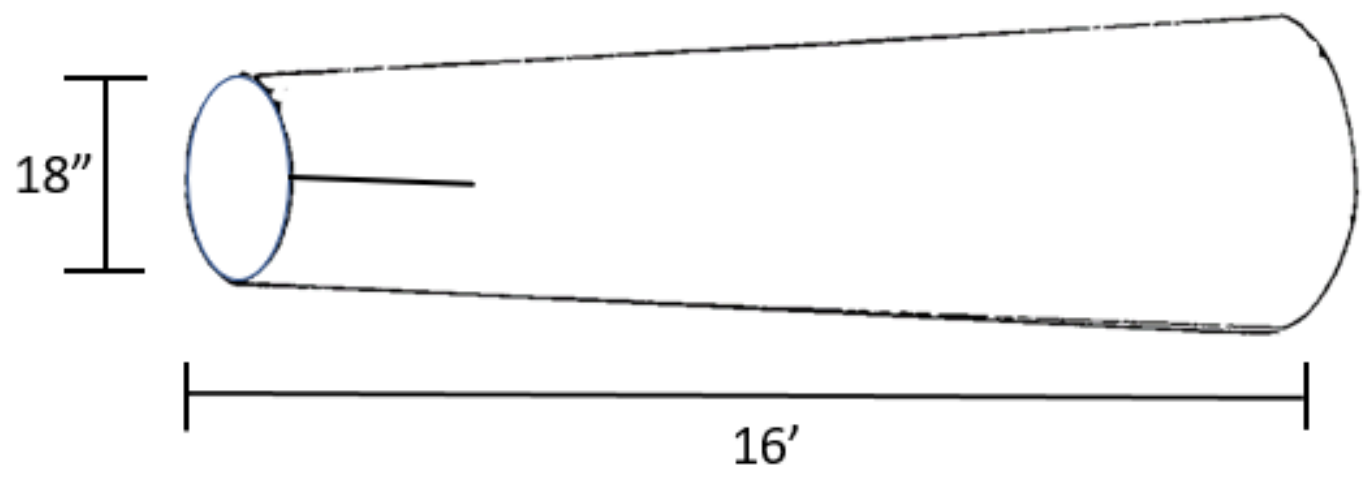

Figure 6. Illustration of a Split in a Hardwood Log. (Graves, 1986)

Spider shake or heart shake is a scaling defect that occurs when there are cracks that extend from near the center of the log to the edges of the log. Spider shake is treated much the same as splits. The scaler must determine how far the spider shake extends into the log. Log length is reduced in two-foot increments, or one-foot increments at the discretion of the sawmill.

Finally, all log scaling and grading data was collected and recorded by hand on a field tally sheet.

\section{Log Grading}

Each log included in the individual log study was examined to determine the total number of clear faces on the log. A face was clear if it contained no defects. Figure 7 provides an example of how a log is broken down into four faces. 


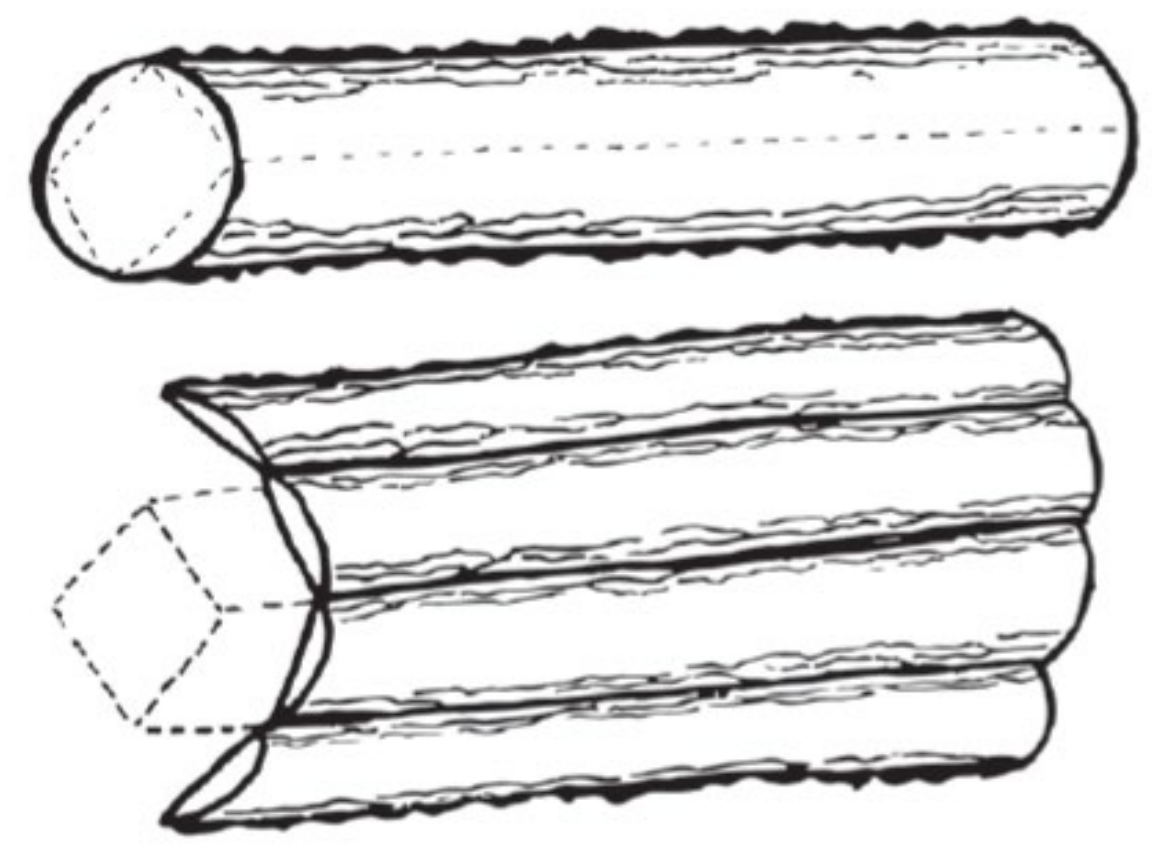

Figure 7. Obtaining Four, Equally Sized Grading Faces. (AHMI 2019)

Grade defects include knots, seams, cracks, holes, bird peck, decay, and abnormally large bumps. Defects located entirely within the trim allowance were ignored (Appalachian Hardwood Manufacturers Inc., 2019).

All logs included in the individual log study were rolled so that all four faces could be observed for defects. This was a crucial step that allowed logs to be graded accurately, since all four faces of every log could be observed.

\section{Mill Processing}

As part of the individual log study, after the logs were scaled and graded, they were processed through the mill.

The steps completed at the cooperating mill for the individual log study approach included the following: 
1. Logs are first sawn on the band headrig, where boards are removed to produce a flitch of standard thickness and random width. Each board sawn off the log at the headrig moves to the optimizing edger, where a study team member marks the board with the log number from which it originated. This person also marks numbers on boards that return to the edger from downstream machine centers. Numbers are written on each side of the board when possible and underlined to avoid any potential confusion. Numbers are placed in the middle of the board widthwise and up several feet from the end. This helps to protect the numbers from being removed either by the edger or trim saw.

2. The flitches are conveyed to a gang saw where multiple boards and a cant sized piece are produced. A second person is stationed at the outfeed of the gang saw to mark numbers on boards. A third person is stationed at the gang saw infeed to relay numbers to the person marking boards on the outfeed side. This is needed to ensure the correct numbers are marked on each board.

3. The cant sized pieces produced through the gang saw are eventually rerouted back to the gang saw for one final pass that produces boards and finished cant size of either 3.5 inches by 6 inches or 5.5 inches by 6 inches. Again, the person on the outfeed of the gang saw marks the log number on each board and cant and on each face of the board when possible.

4. A fourth person is stationed below the trim saw with an NHLA lumber grader. This person records data for each piece produced from every log. For each board, the following data is recorded; thickness, log number, NHLA grade, and 
surface measure. For each cant produced, the width, thickness, and length are recorded.

\section{Individual Log Study Analysis}

Two spreadsheets were utilized to complete the analysis from the individual log study approach. The first spreadsheet was used to sort and organize the lumber data that was gathered during the sawing process. The data entered includes the log number from which the board or cant originated, the thickness of board, the surface measure, and the NHLA grade. Board thickness was recorded and entered in quarter inch increments which is the industry standard for defining thickness of hardwood lumber. For example, a 1" thick board would be recorded as a 4/4 board, while a 2" thick board would be recorded as an $8 / 4$ board.

If the product was a cant, then the width, thickness, and length of the cant was entered. Once all this data is entered, the lumber yields and any cant volumes were sorted by log number. The log number provided a way to track all the products sawn from a specific log.

For this study, lumber volumes produced for each lumber grade were summed, thus providing the lumber grade yields of the log, by lumber grade. Cant volumes were determined by the formula for calculating board foot volume. This formula is $\frac{(\text { width in inches } \times \text { length in feet } \times \text { thickness in inches) }}{12}$, rounded to the nearest whole number (American Hardwood Export Council, 2008). For determining the volume of lumber produced during the study, surface measure was used. The participating sawmill only produced $4 / 4$ lumber during the log studies and when only $4 / 4$ lumber is being 
produced, the board foot volume of a given board equals the surface measure of that board.

The second spreadsheet utilized the sorted lumber grade yields by log obtained from spreadsheet one, as well as log scaling and grading information obtained from the individual logs, including log number, species, scaling diameter, log length, trim length, net scale, and log grade. Also contained in this spreadsheet are sawing costs and product pricing information, which were provided by the participating sawmill and utilized in the analysis.

The Doyle log rule was utilized to calculate the board foot volume of each log. Scaling diameter and length are needed to obtain the board foot volume from the volume table. This table, provided in the appendix, illustrates the Doyle log rule used to determine log volume. The Doyle formula can be used as well, although there are minor rounding differences between the formula and the table. The formula to compute Doyle volume follows:

$$
\begin{gathered}
\text { Doyle Volume }(\mathrm{BF})=(D-4)^{2} \times(L \div 16) \\
\text { where } \mathrm{D}=\text { Scaling Diameter and } \mathrm{L}=\text { Log Length }
\end{gathered}
$$

Using the table or formula to find the board foot volume provides the gross scale of the log. As mentioned previously, this study utilized the rules-of-thumb scaling deductions, where either log length or log diameter is reduced to account for reduced volumes caused by log defects. Any scaling deductions taken from a log will reduce the overall scaling volume. After all deductions are taken, the resulting volume is called the net scale. 
Once the net scale is obtained for each log, overrun or underrun can easily be calculated when lumber grade yields by log are summed. The formula for percent overrun or underrun on an individual log basis is $\frac{\text { Total Lumber Volume }- \text { Net Log Scale }}{\text { Net Log Scale }} \times 100$. The gross revenue for a log is calculated by multiplying the board foot volume for each grade by lumber/cant price for that grade and summing all values. All lumber prices are provided as $\$ / M B F$, so taking the summed value and dividing by 1000 will give the value of the products provided by each log.

The second spreadsheet was also used to determine the percent return for each log included in the study. Three cost figures are needed for each log to obtain the percent return. These costs include the gross revenue (based on lumber grade yields and product price, as described above), the log purchase cost, and sawing cost. Log purchase cost is calculated by taking the gross board foot volume of the log and dividing by the price per MBF paid by the mill for that log grade and dividing by 1000 . Sawing costs are also calculated on an individual log basis. To do so, the total lumber volume from the log is multiplied by the sawing cost per MBF and divided by 1000 . With these values determined, all the necessary information to calculate percent return is available. The formula for determining percent return is: $\frac{(\text { Gross Revenue }- \text { Log Cost }- \text { Sawing Cost) }}{(\text { Log Cost }+ \text { Sawing Cost })} \times 100$.

\section{Batch Study Methods}

The participating sawmill utilizes a clear face grading system. Logs are graded based on the diameter inside the bark (DIB) at the small end of the log and the number of clear faces on the log. The grading system has five options for log grades. They are 
Prime, 1, 2, 3, and Cull. Figure 8 shows how grade changes across diameters and clear faces. For example, a 12-inch log with three or four clear faces is graded based on the log's position in the tree. A butt log would be a Grade 1, while an upper would be a Grade 2 log. Specific grade requirements for these options follow:

- Prime logs must have four clear faces and a scaling diameter of at least 16 inches.

- Grade 1 logs are subdivided into two categories: four clear sided or three clear sided logs with a scaling diameter (DIB) greater than or equal to 12 inches, but less than or equal to 15 inches; or logs with 3 clear faces and 16 inches scaling diameter.

- Grade 2 logs are subdivided into two categories: two clear sides with a scaling diameter greater than or equal to 12 inches, but less than or equal to 15 inches; or 2 clear sides with a scaling diameter (DIB) of 16 inches and greater.

- Grade 3 logs are those with one clear side or any log, regardless of the number of clear sides, that has a diameter (DIB) less than 12 inches.

- Cull logs are those logs with zero clear sides, regardless of diameter.

- This study did not include any Grade 3 or Cull log batches. 


\begin{tabular}{|c|c|c|c|c|c|}
\hline \multirow{2}{*}{$\begin{array}{c}\text { Scaling } \\
\text { Diameter }\end{array}$} & \multicolumn{5}{|c|}{ Clear Faces } \\
\hline$>=17^{\prime \prime}$ & $\mathrm{P}$ & 1 & 2 & 3 & CULL \\
\hline $16^{\prime \prime}$ & $\mathrm{P}$ & 1 & 2 & 3 & CULL \\
\hline $15^{\prime \prime}$ & 1 & 1 & 2 & 3 & CULL \\
\hline $14^{\prime \prime}$ & 1 & 1 & 2 & 3 & CULL \\
\hline $13^{\prime \prime}$ & 1 & 1 & 2 & 3 & CULL \\
\hline $12^{\prime \prime}$ & $\mathrm{B}=1 ; \mathrm{U}=2$ & $\mathrm{~B}=1 ; \mathrm{U}=2$ & 2 & 3 & CULL \\
\hline $11^{\prime \prime}$ & 3 & 3 & 3 & 3 & CULL \\
\hline $10^{\prime \prime}$ & 3 & 3 & 3 & 3 & CULL 2 \\
\hline
\end{tabular}

Figure 8. Log Grading Specifications of the Participating Sawmill.

When logs arrive at the mill, they are scaled and graded by a two-person log inspection crew. Logs are graded as they lay, so at best, the inspectors can observe three faces of the log. No logs are rolled to enable to scalers to view the bottom face. The logs are typically bunched very closely together and in most situations the inspectors are only able to observe one or two of the faces. For the individual log study, logs were rolled so that all four faces were observed by the log inspectors. Rolling the logs eliminated the issues encountered when logs were stacked closely together.

For batch log studies conducted at the mill, the batches were typically organized by log grade. Prime grade batches contained 20 logs each, all other log grades contained 25 logs per batch. As part of this study, log grades 1 and 2 were tested using two separate batches, with one batch containing a smaller set of diameters and the second batch containing larger diameter logs in that grade. Figure 8 is color coded to

\footnotetext{
${ }^{2} \mathrm{~B}=$ Butt Log, $\mathrm{U}=$ Upper
} 
show how the batches were organized. For example, there were two batches that test log grade 2. One batch is comprised of logs 12 to 15 inches in diameter (orange cells in Fig. 8), the second batch contained logs classified as Log Grade 2 and is comprised of logs that are 16 inches DIB and larger (green cells in Fig. 8). Grade 1 logs were also tested with two batches, one containing smaller diameters and the other containing larger diameter logs.

The participating sawmill collected all log scaling and grade data on a handheld computer. For each batch, a printout of batch data was provided. This printout provided the following information for each log: species, grade, length, scaling diameter, board foot volume, price per MBF, and price paid for the log. A rule-of-thumb scaling deduction was used to account for log defects, where either log length or scaling diameter is reduced to account for the volume lost due to log defects (the exact rules-ofthumb were not disclosed to the AHC personnel). However, there was no indication in the printouts of when a scaling deduction was taken on a log, so only the revised scaling diameter or length is recorded. Additionally, the number of clear faces was not indicated on the tally sheets, so clear face information was assumed based on the assigned grade. For example, if the scalers classified a log as grade 2, then only two clear faces should have been observed on the graded log.

However, Grade 1 small diameter batches could contain either three or four clear faces in the grade. Grade 1 small diameter batches contained logs that were 12 "-15" in diameter and having either three or four clear faces on the logs. The number of clear faces on the logs was not recorded on the tally sheets. As such, there was no way to determine the number of clear faces for logs in these batches. 


\section{Comparison of Batch Study vs Individual Log Studies}

\section{Batch Composition}

A primary goal of this work is to determine the amount of variability between the batches in the study, by comparing the frequencies in each cell of the grading table (Figure 8). For example, grade 1 small batches, across all species, will be analyzed to determine if the batches are statistically different from each other. Comparing batches of the same log grade provided insight as to how consistent the batch selection process was. Data were analyzed using JMP and SAS software. Significance criterion for all tests was $\alpha=0.05$.

The Cochran-Mantel-Haenszel (CMH) test was selected over the Pearson chisquare test to identify significant differences between the composition of the batches (Stokes, 2012). Both tests use a chi-square distribution to test for significance, but the $\mathrm{CMH}$ test requires no expected cell frequencies in order to conduct the test. If a Pearson chi-square test had been used for this analysis, diameters would need to be grouped for the testing to ensure that at least $80 \%$ of the cells had an expected frequency of at least five. In contrast, the CHM test allows each diameter represented in the batch to be tested without any need to combine the diameters into groupings. An alpha level of 0.05 was used in all comparisons to test for significance.

To compare batch composition results between the individual log scaling method and the batch study method, a Kappa coefficient agreement statistic was computed. A Kappa coefficient is useful in situations where two or more observers are evaluating the 
same object or person (Vierra 2005). A Kappa coefficient of one indicates that there is perfect agreement between the observers. A Kappa coefficient less than or equal to zero indicates that any agreement occurred only by chance. A commonly cited scale for interpreting Kappa coefficients is provided in Figure 9 (Landis 1977). For each of the 16 batches in this study, the diameter frequencies were compared between the individual log and batch study scaling results. This same analysis was then conducted on log grading results. These two analyses together provided insight as to the degree of agreement among the log scaling and grading results between the two log evaluation teams.

\section{Interpretation of Kappa}

\begin{tabular}{|c|c|c|c|c|c|c|}
\hline & Poor & Slight & Fair & Moderate & Substantial & Almost perfect \\
\hline Cappa & 0.0 & .20 & .40 & .60 & .80 & 1.0 \\
\hline
\end{tabular}

$\begin{array}{ll}\frac{\text { Kappa }}{<0} & \text { Agreement } \\ 0.01-0.20 & \text { Less than chance agreement } \\ 0.21-0.40 & \text { Fair agreement } \\ 0.41-0.60 & \text { Moderate agreement } \\ 0.61-0.80 & \text { Substantial agreement } \\ 0.81-0.99 & \text { Almost perfect agreement }\end{array}$

Figure 9. Interpretation of the Kappa Agreement Statistic. (Landis 1977).

\section{Grade Yield Analysis}

Lumber grade yields between batches were analyzed to determine if batch composition had a statistically significant impact on lumber grade yields. This was done 
using a one-way ANOVA or Wilcoxon/Kruskal-Wallis test, depending on whether the tested lumber yield distributions were normally distributed or non-parametric.

Normality is an assumption that must be tested prior to using an ANOVA. If normality cannot be assumed, the nonparametric Wilcoxon/Kruskal-Wallis method must be used.

The one-way ANOVA was used on normally distributed data, while the Wilcoxon/Kruskal-Wallis test was used on distributions that were non-parametric. An alpha level of 0.05 was used to determine statistical significance in both cases.

A Shapiro-Wilk W test was used to determine if the distribution was normally distributed or nonparametric. The null hypothesis of the Shapiro-Wilk test is that the data are normally distributed. Therefore, any significant $p$-value indicates that the data are not drawn from a normal distribution. The Shapiro-Wilk W test is able to detect nonnormality caused by either skewness or kurtosis. If the Shapiro-Wilk test was significant, at an alpha level of 0.05 , the assumption of normality for an ANOVA was not met and a non-parametric method, either the Wilcoxon or Kruskal-Wallis test, was used.

There are two non-parametric methods that can be used: the Wilcoxon Test and the Kruskal-Wallis test. Both tests are non-parametric alternatives to the one-way ANOVA. These two tests are very similar to each other, with one major difference. The Wilcoxon test is used when there are two groups. The Kruskal-Wallis test is a nonparametric test like the Wilcoxon test, but can accommodate more than two groups. Both the Wilcoxon and Kruskal-Wallis compare the test statistic to a chi-square 
distribution to determine statistical significance. An alpha level of 0.05 was used for all comparisons with this test.

Certain species, for example, soft maple and cherry, have color-based sorts (which could be considered a grade) of the higher quality lumber grades to meet market demand. These color-based lumber grades are unique to these species, as no other species in this study were color sorted in this manner. To make similar lumber grades between species, lumber grades were classified into three broad categories. These categories were One Face and Better (1F+), 1 Common (1C), and finally, 2 Common and below plus cants (2C- CANT).

The cants were combined with the 2 common and below grade lumber because different size cants were manufactured depending on species and the size of the cant would have affected the yield percentage of both lumber and cants. For example, cherry cants were 3.5 " 66 ", while for most other species, 5.5 "x6" cants were sawn.

If cant yield was tested in the analysis as a separate grade, the size of the cant would have skewed the yield percentage of both lumber and cants. To remedy this problem, the cants were grouped with 2 Common and lower lumber. Grouping the cant yield with the 2 Common and lower lumber yields minimized the effect of producing different size cants on grade yield percentages.

The same analysis was then conducted on lumber grade yields between the batch results and the individual log results, to determine if lumber grade yields were significantly different between the two methods. For this individual log analysis, only the logs that fit the batch characteristics were included in the analysis. The non-parametric 
Wilcoxon or Kruskal-Wallis test was used for non-parametric data, while a one-way ANOVA was utilized for analyzing normally distributed data.

\section{Overrun Analysis}

Overrun was analyzed for each of the batch categories and then for the batch versus individual log overrun result. Analysis of overrun was conducted in the same manner as lumber yields. A one-way ANOVA was utilized for normally distributed data, while the Kruskal-Wallace test was utilized for non-parametric distributions. The Shapiro Wilk W test was used to determine if the overrun distributions were normal or nonparametric.

For the individual log analysis, only the logs that fit the batch characteristics were included in the analysis.

\section{Breakeven Pricing Analysis}

A breakeven analysis was conducted for each batch, for a total of 16 separate analyses. Lumber tally by grade was divided by the total lumber tally to determine individual lumber grade yield percentages. The overrun was also calculated for each batch. This information was used, in conjunction with species-based lumber and cant pricing and sawing costs, to determine batch breakeven price.

A breakeven analysis of logs, by diameter and grade, was then completed based on the log scaling and grading results from the participating sawmill. This data was available on the log tally sheet provided for each batch study. Logs were arranged according to diameter/clear face information. For example, all logs that were 13" in diameter with four clear faces, according to the provided tally sheet, were grouped 
together. Once logs were arranged, average lumber yields were calculated, along with the overrun. The lumber grades used for this analysis were: FAS, One Face (1F), 1 Common, 2 Common, 3 Common, and Cant. A breakeven price was determined for each cell in the grading table, based solely on log grading and scaling results from the participating sawmill. The one exception here was the Grade 1 Small Diameter logs, by scaling diameter, where 3 and 4 clear face results are combined and the participating mill grades and scaling results do not provide the number of clear faces for that batch.

The grading table in Figure 8 does not distinguish between species. For example, all 12" DIB logs with two clear faces are assumed to be of the same grade, regardless of species. The assumption of the grading table is that lumber grade yields for each cell of the grading table are the same regardless of species. Therefore, lumber yield data was aggregated for all logs, regardless of species, that were included in the study in each individual cell of the grading table.

The individual log study results were then used to complete a separate breakeven analysis. This analysis used results obtained from the individual log study methods. Each log in the study was arranged by diameter and clear face combinations, so that lumber yields and overrun could be calculated for each cell in the grading table. The lumber grades used for the breakeven analysis were: FAS, One Face, 1 Common, 2 Common, 3 Common, and Cant. Some cells in the grading table had to be skipped due to a lack of a sufficiently large sample size in those cells. The same sawing costs and lumber/cant pricing were used in this portion as was used in the batch study breakeven analysis. Lumber yield percentages and overrun remained the same for all 
species, but species-based lumber/cant pricing and sawing costs were used to calculate breakeven prices.

Finally, batch breakeven prices were calculated again, but using only those logs that truly belonged in the batch, based on log grading and scaling data gathered from the AHC individual log method. This analysis provided insight into the effect of batch composition on the calculated breakeven price, particularly if the batch used in the analysis incorrectly contains logs of a different size or grade.

\section{RESULTS}

\section{Batch Sample Frequencies of Logs}

A Cochran-Mantel-Haenszel test was used to determine if batches within a log grade were statistically different from each other. Five batch categories were tested: Prime, Grade 1 small diameter, Grade 1 large diameter, Grade 2 small diameter, and Grade 2 large diameter.

\section{Prime Grade}

Three batches were tested in the prime grade. This grade contains logs that are 16" DIB and greater at the small end with four clear faces. Each batch consisted of a different species. These species were Red Oak, Yellow-poplar, and Soft Maple. Each batch contained 20 logs. 
For the $\mathrm{CMH}$ analysis, the calculated test statistic was 15.52 , with a corresponding $p$-value of 0.0004 . This suggests that at least one of the three Prime grade batches was statistically different from the others.

\section{Grade 1 Small Diameter}

Five batches with 25 logs in each batch were constructed and studied in this log grade. This grade consists of logs that were 12 " to 15 " DIB at the small end with either three or four clear faces. As mentioned earlier, in this grade there was no way to know how many clear faces the log inspectors at the mill observed. Four species were tested in this log grade, Red Oak, Soft Maple, Cherry, and Yellow-poplar. There were two Yellow-poplar tests that were distinguished based on the month the study was conducted. The first Yellow-poplar study was completed in November, while the second was completed in January.

The $\mathrm{CMH}$ analysis generated a test statistic of 13.80 , which corresponds to a pvalue of 0.0079 and suggests that at least one of the batches was statistically different from the others.

\section{Grade 1 Large Diameter}

Grade 1 large diameter logs are 16" DIB and greater scaling diameter with three clear faces. Three batch studies were constructed and studied in this log grade. Each study batch was composed of a different species; Red Oak, Soft Maple, and Yellowpoplar. There were 25 logs in the Soft Maple and Red Oak batches. There were only 24 
logs in the Yellow-poplar test, because one log had to be removed from the study due to metal contamination in the log.

The $\mathrm{CMH}$ analysis yielded a test statistic of 2.55 . This corresponds to a p-value of 0.28 , which suggests that the three batches were not statistically different from each other.

\section{Grade 2 Small Diameter}

Grade 2 small diameter logs are 12 " to 15 " DIB with two clear faces. There were three batch studies completed in this grade. Each batch was of a different species, with Red Oak, Yellow-poplar, and Cherry being tested. There were 25 logs in each batch.

The $\mathrm{CMH}$ analysis of the Grade 2 small diameter batches had a test statistic of 27.49 , with a corresponding $p$-value of $<0.0001$. This suggests that at least one of the three batches was significantly different from other batches.

\section{Grade 2 Large Diameter}

Grade 2 large diameter logs are 16" and larger, with two clear faces. There were two batches completed in this log grade- Red Oak and Yellow-poplar. There were 25 logs in each batch.

The $\mathrm{CMH}$ analysis generated a test statistic of 19.99 , with a p-value of $<0.0001$, suggesting that the two batches were statistically different from each other. A number of small logs were improperly placed in the Red Oak Grade 2 large diameter batch, with $15(60 \%)$ of the 25 logs in the batch having a scaling diameter of $14 "-15 "$ and were 
actually Grade 2 small diameter logs, which explains in part the statistically significant result.

\section{Comparison of Batch Composition with Individual Log Approach}

The Kappa agreement statistic was used to determine the amount of agreement present among log scaling and grading results between the batch study method and the individual log method. In total, 16 batch studies were included as part of this effort. For each of the 16 batch studies, a Kappa agreement statistic was computed for agreement between diameter measurements and again between log grades. Table 1 provides a summary of the Kappa agreement findings.

\section{Red Oak Grade 2 Small Diameter}

The Kappa agreement statistic calculated for the diameter measurement comparisons between the two methods had a coefficient of 0.29 with a p-value of 0.04 . This means that diameter measurements between the two methods had fair agreement. The statistically significant $p$-value suggested that the agreement is not due to chance.

For the log grade comparison, the Kappa agreement statistic was 0.09 with a corresponding $p$-value of 0.14 . This means that there was slight agreement in log grades between the two methods, but the p-value indicates that any agreement was due to chance. Figure 10 illustrates the frequency distributions of the logs on the mill's grading table. 


\begin{tabular}{|c|c|c|c|c|c|c|c|c|c|c|c|}
\hline \multicolumn{6}{|c|}{ Individual Log Grading and Scaling Results } & \multicolumn{6}{|c|}{ Batch Study Grading and Scaling Results } \\
\hline \multirow{2}{*}{$\begin{array}{l}\text { Scaling } \\
\text { Diameter }\end{array}$} & \multicolumn{5}{|c|}{ Clear Faces } & \multirow{2}{*}{$\begin{array}{l}\text { Scaling } \\
\text { Diameter }\end{array}$} & \multicolumn{5}{|c|}{ Clear Faces } \\
\hline & 4 & 3 & 2 & 1 & 0 & & 4 & 3 & 2 & 1 & 0 \\
\hline$\geq 17^{\prime \prime}$ & & & & & & $\geq 17$ & & & & & \\
\hline 16" & & & & & & $16 "$ & & & & & \\
\hline $15 "$ & & & & & & $15 "$ & & & & & \\
\hline 14" & & & & & & $14 "$ & & & & & \\
\hline 13" & & 2 & 3 & 2 & & $13 "$ & & & 4 & & \\
\hline 12" & & & 15 & & & $12 "$ & & & 21 & & \\
\hline 11" & & & & 3 & & $11 "$ & & & & & \\
\hline 10" & & & & & & $10 "$ & & & & & \\
\hline
\end{tabular}

Figure 10. Comparison of Log Grade Distributions between the Individual Log and

Batch Study Methods for the Grade 2 Small Diameter Red Oak Batch.

\section{Red Oak Grade 2 Large Diameter}

The Kappa agreement statistic for log diameter was 0.62 , with a corresponding $p$-value of $<0.0001$. This indicates that there was substantial agreement in diameter measurements between the individual log study and batch study results. The statistically significant p-value indicates that the agreement was not due to chance.

For the log grade comparison, the Kappa agreement statistic was 0.11 with a pvalue of 0.03 . The Kappa agreement statistic indicates that there was slight agreement in log scaling results between the two approaches, and this agreement was not due to chance according to the statistically significant p-value. Figure 11 illustrates the frequency distributions of logs by diameter and clear faces for both the individual log and batch study methods. 


\begin{tabular}{|c|c|c|c|c|c|c|c|c|c|c|c|}
\hline \multicolumn{6}{|c|}{ Individual Log Grading and Scaling Results } & \multicolumn{6}{|c|}{ Batch Study Grading and Scaling Results } \\
\hline \multirow{2}{*}{$\begin{array}{l}\text { Scaling } \\
\text { Diameter }\end{array}$} & \multicolumn{5}{|c|}{ Clear Faces } & \multirow{2}{*}{$\begin{array}{l}\text { Scaling } \\
\text { Diameter }\end{array}$} & \multicolumn{5}{|c|}{ Clear Faces } \\
\hline & 4 & 3 & 2 & 1 & 0 & & 4 & 3 & 2 & 1 & 0 \\
\hline$\geq 17^{\prime \prime}$ & & 2 & & 2 & & $\geq 17^{\prime \prime}$ & & & 4 & & \\
\hline $16 "$ & & 3 & & 2 & & $16 "$ & & & 6 & & \\
\hline $15^{\prime \prime}$ & & 1 & 1 & 2 & & $15^{\prime \prime}$ & & & 5 & & \\
\hline $14 "$ & 1 & 4 & 6 & & & $14 "$ & & & 10 & & \\
\hline $13^{\prime \prime}$ & & & 1 & & & $13^{\prime \prime}$ & & & & & \\
\hline $12^{\prime \prime}$ & & & & & & $12^{\prime \prime}$ & & & & & \\
\hline $11^{\prime \prime}$ & & & & & & $11 "$ & & & & & \\
\hline $10 "$ & & & & & & $10 "$ & & & & & \\
\hline
\end{tabular}

Figure 11. Comparison of Log Grade Distributions between the Individual Log and Batch Study Methods for the Grade 2 Large Diameter Red Oak Batch.

\section{Red Oak Grade 1 Small Diameter}

For the log diameter analysis, the Kappa statistic was 0.54 with a $p$-value of $<0.0001$. This indicates that there was moderate agreement in diameter measurements between the two methodologies. The statistically significant $p$-value indicates that the moderate agreement was not due to chance.

For the log grade comparison, the Kappa statistic was also 0.54 with a p-value of $<0.0001$. This means there was moderate agreement in log grades between the two methods, and this agreement was not due to chance because of the highly significant $p$ value. Figure 12 illustrates the frequency distributions of logs according to both the individual log and batch mill study methods. 


\begin{tabular}{|c|c|c|c|c|c|c|c|c|c|c|c|}
\hline \multicolumn{6}{|c|}{ Individual Log Grading and Scaling Results } & \multicolumn{6}{|c|}{ Batch Study Grading and Scaling Results } \\
\hline \multirow{2}{*}{$\begin{array}{l}\text { Scaling } \\
\text { Diameter }\end{array}$} & \multicolumn{5}{|c|}{ Clear Faces } & \multirow{2}{*}{$\begin{array}{l}\text { Scaling } \\
\text { Diameter }\end{array}$} & \multicolumn{5}{|c|}{ Clear Faces } \\
\hline & 4 & 3 & 2 & 1 & 0 & & 4 & 3 & 2 & 1 & 0 \\
\hline$\geq 17^{\prime \prime}$ & & & & & & $\geq 17^{\prime \prime}$ & & & & & \\
\hline $16 "$ & 1 & & & & & $16 "$ & & & & & \\
\hline $15^{\prime \prime}$ & 4 & 3 & & & & $15 "$ & & & & & \\
\hline $14 "$ & 3 & 1 & & & & $14 "$ & & & & & \\
\hline $13^{\prime \prime}$ & 4 & 7 & & & & $13 "$ & & & & & \\
\hline $12 "$ & 2 & & & & & $12 "$ & & & & & \\
\hline $11^{\prime \prime}$ & & & & & & $11 "$ & & & & & \\
\hline 10" & & & & & & 10" & & & & & \\
\hline
\end{tabular}

Figure 12. Comparison of Log Grade Distributions between the Individual Log and

Batch Study Methods for the Grade 1 Small Diameter Red Oak Batch.

\section{Red Oak Grade 1 Large Diameter}

For the diameter comparison, the Kappa agreement statistic was 0.30 with a pvalue of 0.07 , indicating that there was fair agreement in diameter measurements between the two methods, however the p-value indicates that this agreement was due to chance.

For the log grade comparison, the Kappa agreement statistic was 0.04 with a pvalue of 0.59 . This indicates that there was very slight agreement in log scaling results between the two methods, but this slight agreement was due entirely to chance. Overall, the log grades between the individual log method and batch method are very different from each other. Figure 13 illustrates the frequency distributions of logs in the grading table according to both the individual log method and batch study method. 


\begin{tabular}{|c|c|c|c|c|c|c|c|c|c|c|c|}
\hline \multicolumn{6}{|c|}{ Individual Log Grading and Scaling Results } & \multicolumn{6}{|c|}{ Batch Study Grading and Scaling Results } \\
\hline \multirow{2}{*}{$\begin{array}{l}\text { Scaling } \\
\text { Diameter }\end{array}$} & \multicolumn{5}{|c|}{ Clear Faces } & \multirow{2}{*}{$\begin{array}{l}\text { Scaling } \\
\text { Diameter }\end{array}$} & \multicolumn{5}{|c|}{ Clear Faces } \\
\hline & 4 & 3 & 2 & 1 & 0 & & 4 & 3 & 2 & 1 & 0 \\
\hline$\geq 17^{\prime \prime}$ & 3 & 9 & 4 & 2 & & $\geq 17^{\prime \prime}$ & & 15 & & & \\
\hline $16^{\prime \prime}$ & 3 & 2 & 1 & 1 & & $16^{\prime \prime}$ & & 10 & & & \\
\hline $15^{\prime \prime}$ & & & & & & $15^{\prime \prime}$ & & & & & \\
\hline $14 "$ & & & & & & $14 "$ & & & & & \\
\hline $13^{\prime \prime}$ & & & & & & $13^{\prime \prime}$ & & & & & \\
\hline $12 "$ & & & & & & $12^{\prime \prime}$ & & & & & \\
\hline $11 "$ & & & & & & $11 "$ & & & & & \\
\hline $10 "$ & & & & & & $10^{\prime \prime}$ & & & & & \\
\hline
\end{tabular}

Figure 13. Comparison of Log Grade Distributions between the Individual Log and Batch Study Methods for the Grade 1 Large Diameter Red Oak Batch.

\section{Red Oak Prime:}

The Kappa agreement statistic for the diameter analysis was 0.64 with a p-value of 0.002 . This indicates that there was substantial agreement in diameter measurements between the individual log and batch study methods. This agreement was not due to chance, as indicated by the statistically significant p-value.

The Kappa agreement statistic for the log grade analysis was 0.22 with a p-value of 0.06 . This indicates that there was fair agreement between the two methods. According to the marginally significant p-value, the fair agreement that was observed between the two methods was due to chance. Figure 14 illustrates the frequency distributions of logs according to both the individual log and batch study methods. 


\begin{tabular}{|c|c|c|c|c|c|c|c|c|c|c|c|}
\hline \multicolumn{6}{|c|}{ Individual Log Grading and Scaling Results } & \multicolumn{6}{|c|}{ Batch Study Grading and Scaling Results } \\
\hline \multirow{2}{*}{$\begin{array}{l}\text { Scaling } \\
\text { Diameter }\end{array}$} & \multicolumn{5}{|c|}{ Clear Faces } & \multirow{2}{*}{$\begin{array}{l}\text { Scaling } \\
\text { Diameter }\end{array}$} & \multicolumn{5}{|c|}{ Clear Faces } \\
\hline & 4 & 3 & 2 & 1 & 0 & & 4 & 3 & 2 & 1 & 0 \\
\hline$\geq 17 "$ & 15 & 3 & 1 & & & $\geq 17^{\prime \prime}$ & 18 & & & & \\
\hline $16 "$ & 1 & & & & & $16 "$ & 2 & & & & \\
\hline $15^{\prime \prime}$ & & & & & & $15^{\prime \prime}$ & & & & & \\
\hline $14 "$ & & & & & & $14 "$ & & & & & \\
\hline $13^{\prime \prime}$ & & & & & & $13^{\prime \prime}$ & & & & & \\
\hline $12 "$ & & & & & & $12 "$ & & & & & \\
\hline $11^{\prime \prime}$ & & & & & & $11 "$ & & & & & \\
\hline $10 "$ & & & & & & $10 "$ & & & & & \\
\hline
\end{tabular}

Figure 14. Comparison of Log Grade Distributions between the Individual Log and Batch Study Methods for the Prime Grade Red Oak Batch.

\section{Yellow-poplar Prime}

The Kappa agreement statistic for the diameter analysis was 0.64 with a p-value of $<0.01$. This indicates substantial, statistically significant, agreement between the batch study and individual log study methods and are not due to chance.

The Kappa agreement statistic for the log grade analysis was 0.59 with a p-value of $<0.01$. This indicates statistically significant moderate agreement in log grades between the two methods and are not due to chance. Figure 15 illustrates the frequency distributions of logs according to the log grading and scaling results for each of the two methods. 


\begin{tabular}{|c|c|c|c|c|c|c|c|c|c|c|c|}
\hline \multicolumn{6}{|c|}{ Individual Log Grading and Scaling Results } & \multicolumn{6}{|c|}{ Batch Study Grading and Scaling Results } \\
\hline \multirow{2}{*}{$\begin{array}{l}\text { Scaling } \\
\text { Diameter }\end{array}$} & \multicolumn{5}{|c|}{ Clear Faces } & \multirow{2}{*}{$\begin{array}{l}\text { Scaling } \\
\text { Diameter }\end{array}$} & \multicolumn{5}{|c|}{ Clear Faces } \\
\hline & 4 & 3 & 2 & 1 & 0 & & 4 & 3 & 2 & 1 & 0 \\
\hline$\geq 17^{\prime \prime}$ & 17 & 2 & & & & $\geq 17 "$ & 18 & & & & \\
\hline $16 "$ & 1 & & & & & $16 "$ & 2 & & & & \\
\hline $15^{\prime \prime}$ & & & & & & $15^{\prime \prime}$ & & & & & \\
\hline $14 "$ & & & & & & $14 "$ & & & & & \\
\hline $13^{\prime \prime}$ & & & & & & $13^{\prime \prime}$ & & & & & \\
\hline $12^{\prime \prime}$ & & & & & & $12 "$ & & & & & \\
\hline $11 "$ & & & & & & $11^{\prime \prime}$ & & & & & \\
\hline $10 "$ & & & & & & $10 "$ & & & & & \\
\hline
\end{tabular}

Figure 15. Comparison of Log Grade Distributions between the Individual Log and Batch Study Methods for the Prime Grade Yellow-poplar Batch.

\section{Yellow-poplar Grade 1 Small Diameter November}

The Kappa agreement statistic for the diameter analysis was 0.57 , with a $p$-value of $<0.01$, which indicated moderate agreement between the two methods. The statistically significant $p$-value indicates that the agreement did not occur by chance.

The Kappa agreement statistic for the log grade analysis was 0.52 with a p-value of $<0.01$. This indicates moderate agreement between the batch study and individual log study methods. The statistically significant $p$-value indicates that this agreement did not occur by chance. Figure 16 provides the frequency distributions of logs based on log grading and scaling results for both the batch study and individual log study. 


\begin{tabular}{|c|c|c|c|c|c|c|c|c|c|c|c|}
\hline \multicolumn{6}{|c|}{ Individual Log Grading and Scaling Results } & \multicolumn{6}{|c|}{ Batch Study Grading and Scaling Results } \\
\hline \multirow{2}{*}{$\begin{array}{l}\text { Scaling } \\
\text { Diameter }\end{array}$} & \multicolumn{5}{|c|}{ Clear Faces } & \multirow{2}{*}{$\begin{array}{l}\text { Scaling } \\
\text { Diameter }\end{array}$} & \multicolumn{5}{|c|}{ Clear Faces } \\
\hline & 4 & 3 & 2 & . & 0 & & 4 & 3 & 2 & 1 & 0 \\
\hline$\geq 17^{\prime \prime}$ & & & & & & $\geq 17$ & & & & & \\
\hline $16 "$ & & & & & & $16^{\prime}$ & & & & & \\
\hline $15 "$ & 3 & & & & & $15^{\prime}$ & & & & & \\
\hline $14 "$ & 7 & 2 & & & & $14^{\prime}$ & & & & & \\
\hline $13^{\prime \prime}$ & 7 & 3 & 1 & & & $13^{\prime}$ & & & & & \\
\hline $12 "$ & & 1 & & & & $12^{\prime}$ & & & & & \\
\hline $11 "$ & & & & & & $11^{\prime}$ & & & & & \\
\hline 10" & & & & & & $10^{\prime}$ & & & & & \\
\hline
\end{tabular}

Figure 16. Comparison of Log Grade Distributions between the Individual Log and

Batch Study Methods for the November Grade 1 Small Diameter Yellow-poplar Batch.

\section{Yellow-poplar Grade 1 Small Diameter January}

For the diameter analysis, the Kappa agreement statistic was 0.41 , with a pvalue of $<0.01$. The Kappa agreement statistic indicates moderate agreement between the batch study and individual log study methods. The statistically significant p-value indicates that the agreement did not occur by chance.

For the grade analysis, the Kappa agreement statistic was 0.41 , with a p-value of $<0.01$. The statistically significant $p$-value indicates that the observed agreement between the batch study and individual log methods did not occur by chance. Figure 17 provides the grading table with the log grading and scaling results for the two methods. 


\begin{tabular}{|c|c|c|c|c|c|c|c|c|c|c|c|}
\hline \multicolumn{6}{|c|}{ Individual Log Grading and Scaling Results } & \multicolumn{6}{|c|}{ Batch Study Grading and Scaling Results } \\
\hline \multirow{2}{*}{$\begin{array}{l}\text { Scaling } \\
\text { Diameter }\end{array}$} & \multicolumn{5}{|c|}{ Clear Faces } & \multirow{2}{*}{$\begin{array}{l}\text { Scaling } \\
\text { Diameter }\end{array}$} & \multicolumn{5}{|c|}{ Clear Faces } \\
\hline & 4 & 3 & 2 & 1 & 0 & & 4 & 3 & 2 & 1 & 0 \\
\hline$\geq 17^{\prime \prime}$ & & & & & & $\geq 17^{\prime \prime}$ & & & & & \\
\hline $16 "$ & 1 & & & & & $16 "$ & & & & & \\
\hline $15^{\prime \prime}$ & 5 & 3 & & & & 15" & & & & & \\
\hline $14 "$ & 5 & 3 & & & & $14 "$ & & & & & \\
\hline $13 "$ & 6 & 2 & & & & $13 "$ & & & & & \\
\hline $12 "$ & & & & & & $12 "$ & & & & & \\
\hline $11 "$ & & & & & & $11 "$ & & & & & \\
\hline $10 "$ & & & & & & $10 "$ & & & & & \\
\hline
\end{tabular}

Figure 17. Comparison of Log Grade Distributions between the Individual Log and

Batch Study Methods for the January Grade 1 Small Diameter Yellow-poplar Batch.

\section{Yellow-poplar Grade 1 Large Diameter}

The Kappa agreement statistic for the diameter analysis was 0.64 with a p-value of $<0.01$. The Kappa agreement statistic indicates substantial agreement in diameter measurements between the batch study method and the individual log study method. The statistically significant p-value indicates that the observed agreement did not occur by chance.

The Kappa agreement statistic for the grade analysis was 0.12 with a $p$-value of $<0.01$. A Kappa agreement statistic of 0.12 indicates slight agreement in log grade results between the batch study method and the individual log study method. The statistically significant $p$-value indicates that the slight agreement between the two methods did not occur by chance. Figure 18 provides the log grading and scaling results for both the individual log study method and the batch study method. 


\begin{tabular}{|c|c|c|c|c|c|c|c|c|c|c|c|}
\hline \multicolumn{6}{|c|}{ Individual Log Grading and Scaling Results } & \multicolumn{6}{|c|}{ Batch Study Grading and Scaling Results } \\
\hline \multirow{2}{*}{$\begin{array}{l}\text { Scaling } \\
\text { Diameter }\end{array}$} & \multicolumn{5}{|c|}{ Clear Faces } & \multirow{2}{*}{$\begin{array}{l}\text { Scaling } \\
\text { Diameter }\end{array}$} & \multicolumn{5}{|c|}{ Clear Faces } \\
\hline & 4 & 3 & 2 & 1 & 0 & & 4 & 3 & 2 & 1 & 0 \\
\hline$\geq 17 "$ & 8 & 7 & 3 & 2 & & $\geq 17^{\prime \prime}$ & & 18 & & & \\
\hline $16^{\prime \prime}$ & 3 & & & & & $16^{\prime \prime}$ & & 6 & & & \\
\hline 15" & 1 & & & & & $15^{\prime \prime}$ & & & & & \\
\hline 14" & & & & & & 14" & & & & & \\
\hline $13^{\prime \prime}$ & & & & & & $13^{\prime \prime}$ & & & & & \\
\hline $12^{\prime \prime}$ & & & & & & 12" & & & & & \\
\hline $11 "$ & & & & & & $11 "$ & & & & & \\
\hline $10 "$ & & & & & & $10 "$ & & & & & \\
\hline
\end{tabular}

Figure 18. Comparison of Log Grade Distributions between the Individual Log and Batch Study Methods for the Grade 1 Large Diameter Yellow-poplar Batch.

\section{Yellow-poplar Grade 2 Small Diameter}

The Kappa agreement statistic for the diameter analysis was 0.41 with a p-value of $<0.01$. A Kappa agreement statistic of 0.41 indicates moderate agreement in diameter measurements between the batch study and individual log study methods. The statistically significant $p$-value indicates that the observed agreement did not occur by chance.

The Kappa agreement statistic for the log grade analysis was 0.09 with a p-value of 0.15 . This indicates that there was slight agreement in log grading results between the two methods. The p-value indicates that the observed agreement occurred simply by chance. Figure 19 provides the log grading and scaling results for both the batch study and individual log study methods. 


\begin{tabular}{|c|c|c|c|c|c|c|c|c|c|c|c|}
\hline \multicolumn{6}{|c|}{ Individual Log Grading and Scaling Results } & \multicolumn{6}{|c|}{ Batch Study Grading and Scaling Results } \\
\hline \multirow{2}{*}{$\begin{array}{l}\text { Scaling } \\
\text { Diameter }\end{array}$} & \multicolumn{5}{|c|}{ Clear Faces } & \multirow{2}{*}{$\begin{array}{l}\text { Scaling } \\
\text { Diameter }\end{array}$} & \multicolumn{5}{|c|}{ Clear Faces } \\
\hline & 4 & 3 & 2 & & 0 & & 4 & 3 & 2 & 1 & 0 \\
\hline$\geq 177^{\prime \prime}$ & & & & & & $\geq 17^{\prime \prime}$ & & & & & \\
\hline $16^{\prime \prime}$ & & & & & & $16 "$ & & & & & \\
\hline 15" & & & & & & $15 "$ & & & 3 & & \\
\hline 14" & & 1 & & & & 14" & & & 6 & & \\
\hline $13^{\prime \prime}$ & 5 & 4 & & & & $13^{\prime \prime}$ & & & 14 & & \\
\hline $12^{\prime \prime}$ & & & & & & $12 "$ & & & 2 & & \\
\hline $11 "$ & & & & & & $11 "$ & & & & & \\
\hline $10 "$ & & & & & & $10 "$ & & & & & \\
\hline
\end{tabular}

Figure 19. Comparison of Log Grade Distributions between the Individual Log and Batch Study Methods for the Grade 2 Small Diameter Yellow-poplar Batch.

\section{Yellow-poplar Grade 2 Large Diameter}

The Kappa agreement statistic for the diameter analysis was 0.36 with a p-value of 0.02 . This indicated fair, statistically significant, agreement in diameter measurements between the batch study and individual log study methods. The statistically significant $p$-value indicated that the observed agreement was not due to chance.

The Kappa agreement statistic for the log grade analysis was 0.09 with a p-value of 0.20 . This indicated slight agreement in log grades between the two methods. The $p-$ value of 0.20 indicates that the observed agreement occurred simply by chance. Figure 20 provides the log grading and scaling results for both the batch study and individual log study methods. 


\begin{tabular}{|c|c|c|c|c|c|c|c|c|c|c|c|}
\hline \multicolumn{6}{|c|}{ Individual Log Grading and Scaling Results } & \multicolumn{6}{|c|}{ Batch Study Grading and Scaling Results } \\
\hline \multirow{2}{*}{$\begin{array}{l}\text { Scaling } \\
\text { Diameter }\end{array}$} & \multicolumn{5}{|c|}{ Clear Faces } & \multirow{2}{*}{$\begin{array}{l}\text { Scaling } \\
\text { Diameter }\end{array}$} & \multicolumn{5}{|c|}{ Clear Faces } \\
\hline & 4 & 3 & 2 & & 0 & & 4 & 3 & 2 & 1 & 0 \\
\hline$\geq 17^{\prime \prime}$ & & 4 & & & & $\geq 17^{\prime \prime}$ & & & 18 & & \\
\hline $16^{\prime \prime}$ & & 4 & & & & $16 "$ & & & 7 & & \\
\hline 15" & & 2 & & & & $15 "$ & & & & & \\
\hline $14 "$ & & & & & & 14" & & & & & \\
\hline $13^{\prime \prime}$ & & & & & & $13^{\prime \prime}$ & & & & & \\
\hline $12^{\prime \prime}$ & & & & & & $12 "$ & & & & & \\
\hline $11 "$ & & & & & & $11 "$ & & & & & \\
\hline 10" & & & & & & 10" & & & & & \\
\hline
\end{tabular}

Figure 20. Comparison of Log Grade Distributions between the Individual Log and Batch Study Methods for the Grade 2 Large Diameter Yellow-poplar Batch.

\section{Soft Maple Prime}

For the diameter analysis, the Kappa agreement statistic was 0.61 with a p-value of $<0.01$. The Kappa agreement statistic indicated substantial agreement in diameter measurements between the batch study and individual log study methods. This agreement was not due to chance, as indicated by the statistically significant $p$-value.

For the log grade analysis, the Kappa agreement statistic was 0.30 with a pvalue of 0.02 . This indicated that there was fair agreement in log grades between the two methods, and this agreement was not due to chance. Figure 21 provides the log grading and scaling results for both the individual log and batch study methods. 


\begin{tabular}{|c|c|c|c|c|c|c|c|c|c|c|c|}
\hline \multicolumn{6}{|c|}{ Individual Log Grading and Scaling Results } & \multicolumn{6}{|c|}{ Batch Study Grading and Scaling Results } \\
\hline \multirow{2}{*}{$\begin{array}{l}\text { Scaling } \\
\text { Diameter }\end{array}$} & \multicolumn{5}{|c|}{ Clear Faces } & \multirow{2}{*}{$\begin{array}{l}\text { Scaling } \\
\text { Diameter }\end{array}$} & \multicolumn{5}{|c|}{ Clear Faces } \\
\hline & 4 & 3 & 2 & 1 & 0 & & 4 & 3 & 2 & 1 & 0 \\
\hline$\geq 17^{\prime \prime}$ & 10 & 3 & 1 & & & $\geq 17^{\prime \prime}$ & 13 & & & & \\
\hline 16" & 4 & 2 & & & & $16 "$ & 7 & & & & \\
\hline $15^{\prime \prime}$ & & & & & & $15^{\prime \prime}$ & & & & & \\
\hline 14" & & & & & & 14" & & & & & \\
\hline 13" & & & & & & 13" & & & & & \\
\hline 12" & & & & & & 12" & & & & & \\
\hline 11" & & & & & & 11" & & & & & \\
\hline 10" & & & & & & 10" & & & & & \\
\hline
\end{tabular}

Figure 21. Comparison of Log Grade Distributions between the Individual Log and Batch Study Methods for the Prime Grade Soft Maple Batch.

\section{Soft Maple Grade 1 Small Diameter}

The Kappa agreement statistic for the diameter analysis was 0.68 with a p-value of $<0.01$. This indicated that there was substantial agreement among diameter measurements between the batch study and the individual log study. The statistically significant p-value indicates that the observed agreement was not due to chance.

The Kappa agreement statistic for the log grade analysis was 0.46 with a p-value of $<0.01$. This indicated that there was moderate agreement in log grades between the batch study and individual log study methods. The statistically significant $p$-value indicated that the observed agreement was not due to chance. Figure 22 provides the log grading and scaling results for both the individual log study and batch study methods. 


\begin{tabular}{|c|c|c|c|c|c|c|c|c|c|c|c|}
\hline \multicolumn{6}{|c|}{ Individual Log Grading and Scaling Results } & \multicolumn{6}{|c|}{ Batch Study Scaling and Grading Results } \\
\hline \multirow{2}{*}{$\begin{array}{l}\text { Scaling } \\
\text { Diameter }\end{array}$} & \multicolumn{5}{|c|}{ Clear Faces } & \multirow{2}{*}{$\begin{array}{l}\text { Scaling } \\
\text { Diameter }\end{array}$} & \multicolumn{5}{|c|}{ Clear Faces } \\
\hline & 4 & 3 & 2 & & 0 & & 4 & 3 & 2 & 1 & 0 \\
\hline$\geq 17 "$ & 1 & & & & & $\geq 17^{\prime \prime}$ & & & & & \\
\hline $16^{\prime \prime}$ & & & & & & $16 "$ & & & & & \\
\hline $15^{\prime \prime}$ & 3 & & 1 & & & $15^{\prime \prime}$ & & & & & \\
\hline 14" & 4 & 1 & & & & $14 "$ & & & & & \\
\hline $13^{\prime \prime}$ & 1 & 4 & 1 & & & $13^{\prime \prime}$ & & & & & \\
\hline $12 "$ & 2 & 2 & 1 & & & $12 "$ & & & & & \\
\hline $11 "$ & 1 & & & & & $11 "$ & & & & & \\
\hline $10^{\prime \prime}$ & & & & & & $10 "$ & & & & & \\
\hline
\end{tabular}

Figure 22. Comparison of Log Grade Distributions between the Individual Log and Batch Study Methods for the Grade 1 Small Diameter Soft Maple Batch.

\section{Soft Maple Grade 1 Large Diameter}

The Kappa agreement statistic for the diameter analysis was 0.56 with a p-value of $<0.01$. This indicated moderate agreement among diameter measurements between the batch study and individual log study methods. The statistically significant $p$-value indicated that the observed agreement was not due to chance.

The Kappa agreement statistic for the log grade analysis was 0.01 with a $p$-value of 0.89 . This indicated slight agreement between the two methods, however the observed agreement was simply due to chance. Figure 23 provides the log grading and scaling results for both the individual log and batch study methods. 


\begin{tabular}{|c|c|c|c|c|c|c|c|c|c|c|c|}
\hline \multicolumn{6}{|c|}{ Individual Log Grading and Scaling Results } & \multicolumn{6}{|c|}{ Batch Study Grading and Scaling Results } \\
\hline \multirow{2}{*}{$\begin{array}{l}\text { Scaling } \\
\text { Diameter }\end{array}$} & \multicolumn{5}{|c|}{ Clear Faces } & \multirow{2}{*}{$\begin{array}{l}\text { Scaling } \\
\text { Diameter }\end{array}$} & \multicolumn{5}{|c|}{ Clear Faces } \\
\hline & 4 & 3 & 2 & & 0 & & 4 & 3 & 2 & 1 & 0 \\
\hline$\geq 17^{\prime \prime}$ & 8 & 3 & & & & $\geq 17^{\prime \prime}$ & & 13 & & & \\
\hline $16 "$ & 3 & 5 & & & & $16 "$ & & 11 & & & \\
\hline $15 "$ & & 1 & & & & $15^{\prime \prime}$ & & & & & \\
\hline $14 "$ & & 1 & & & & $14 "$ & & & & & \\
\hline $13 "$ & & & & & & $13^{\prime \prime}$ & & & & & \\
\hline $12 "$ & & & & & & $12 "$ & & & & & \\
\hline $11 "$ & & & & & & $11 "$ & & & & & \\
\hline $10 "$ & & & & & & $10^{\prime \prime}$ & & & & & \\
\hline
\end{tabular}

Figure 23. Comparison of Log Grade Distributions between the Individual Log and Batch Study Methods for the Grade 1 Large Diameter Soft Maple Batch.

\section{Cherry Grade 1 Small Diameter}

For the diameter analysis, the Kappa agreement statistic was 0.69 with a p-value of $<0.01$. This indicated that there was substantial agreement in diameter measurements between the batch study and individual log study methods. The statistically significant $p$-value indicated that the observed agreement was not due to chance.

For the log grade analysis, the Kappa agreement statistic was 0.51 with a pvalue of $<0.01$. This indicated moderate agreement among log grades between the batch study and individual log study methods. The statistically significant p-value indicated that the observed agreement was not due to chance. Figure 24 provides a comparison of log grading and scaling results between the two methods. 


\begin{tabular}{|c|c|c|c|c|c|c|c|c|c|c|c|}
\hline \multicolumn{6}{|c|}{ Individual Log Grading and Scaling Results } & \multicolumn{6}{|c|}{ Batch Study Grading and Scaling Results } \\
\hline \multirow{2}{*}{$\begin{array}{l}\text { Scaling } \\
\text { Diameter }\end{array}$} & \multicolumn{5}{|c|}{ Clear Faces } & \multirow{2}{*}{$\begin{array}{l}\text { Scaling } \\
\text { Diameter }\end{array}$} & \multicolumn{5}{|c|}{ Clear Faces } \\
\hline & 4 & 3 & 2 & 1 & 0 & & 4 & 3 & 2 & 1 & 0 \\
\hline$\geq 17 "$ & & & & & & $\geq 17^{\prime \prime}$ & & & & & \\
\hline $16^{\prime \prime}$ & 1 & 1 & & & & $16 "$ & & & & & \\
\hline $15^{\prime \prime}$ & 4 & 4 & & & & $15^{\prime \prime}$ & & & & & \\
\hline 14" & 5 & 2 & 4 & & & $14 "$ & & & & & \\
\hline $13^{\prime \prime}$ & 2 & & & & & $13^{\prime \prime}$ & & & & & \\
\hline $12 "$ & 1 & & 1 & & & $12 "$ & & & & & \\
\hline $11 "$ & & & & & & $11 "$ & & & & & \\
\hline $10^{\prime \prime}$ & & & & & & $10 "$ & & & & & \\
\hline
\end{tabular}

Figure 24. Comparison of Log Grade Distributions between the Individual Log and Batch Study Methods for the Grade 1 Small Diameter Cherry Batch.

\section{Cherry Grade 2 Small Diameter}

For the diameter analysis, the Kappa agreement statistic was 0.46 with a p-value of $<0.01$. This indicated that there was moderate agreement among diameter measurements between the batch study and individual log study. The statistically significant p-value indicated that the observed agreement was not due to chance.

For the log grade analysis, the Kappa agreement statistic was 0.18 with a pvalue of $<0.01$. This indicated that there was slight agreement in log grading results between the two methods. The statistically significant $p$-value indicated that the observed agreement was not due to chance. Figure 25 provides a comparison of log grading and scaling results between the individual log and batch study methods. 


\begin{tabular}{|c|c|c|c|c|c|c|c|c|c|c|c|}
\hline \multicolumn{6}{|c|}{ Individual Log Grading and Scaling Results } & \multicolumn{6}{|c|}{ Batch Study Scaling and Grading Results } \\
\hline \multirow{2}{*}{$\begin{array}{l}\text { Scaling } \\
\text { Diameter }\end{array}$} & \multicolumn{5}{|c|}{ Clear Faces } & \multirow{2}{*}{$\begin{array}{l}\text { Scaling } \\
\text { Diameter }\end{array}$} & \multicolumn{5}{|c|}{ Clear Faces } \\
\hline & 4 & 3 & 2 & & 0 & & 4 & 3 & 2 & 1 & 0 \\
\hline$\geq 17 "$ & & & & & & $\geq 17^{\prime \prime}$ & & & & & \\
\hline $16^{\prime \prime}$ & & 2 & & & & $16 "$ & & & & & \\
\hline $15^{\prime \prime}$ & & 2 & 1 & & & $15^{\prime \prime}$ & & & 4 & & \\
\hline 14" & & 2 & 4 & 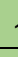 & & $14 "$ & & & 7 & & \\
\hline $13^{\prime \prime}$ & 1 & 4 & 4 & - & & $13^{\prime \prime}$ & & & 9 & & \\
\hline $12 "$ & & & 3 & & & $12 "$ & & & 5 & & \\
\hline $11 "$ & & & & & & $11 "$ & & & & & \\
\hline $10 "$ & & & & & & $10 "$ & & & & & \\
\hline
\end{tabular}

Figure 25. Comparison of Log Grade Distributions between the Individual Log and Batch Study Methods for the Grade 2 Small Diameter Cherry Batch. 
Table 1. Summary of the Kappa Agreement Statistic Results.

\begin{tabular}{|c|c|c|c|c|c|c|}
\hline Species & Log Grade & Measurement & Kappa & $p$-value & Agreement & Cause of Agreement \\
\hline \multirow{2}{*}{ Red Oak } & Grade 2 & Diameter & 0.29 & 0.04 & Fair & Not by Chance \\
\hline & Small & Grade & 0.09 & 0.14 & Slight & Chance \\
\hline \multirow{2}{*}{ Red Oak } & Grade 2 & Diameter & 0.62 & $<0.01$ & Substantial & Not by Chance \\
\hline & Large & Grade & 0.11 & 0.03 & Slight & Not by Chance \\
\hline \multirow{2}{*}{ Red Oak } & Grade 1 & Diameter & 0.54 & $<0.01$ & Moderate & Not by Chance \\
\hline & Small & Grade & 0.54 & $<0.01$ & Moderate & Not by Chance \\
\hline \multirow{2}{*}{ Red Oak } & Grade 1 & Diameter & 0.30 & 0.07 & Fair & Chance \\
\hline & Large & Grade & 0.04 & 0.59 & Slight & Chance \\
\hline \multirow{2}{*}{ Red Oak } & \multirow{2}{*}{ Prime } & Diameter & 0.64 & $<0.01$ & Substantial & Not by Chance \\
\hline & & Grade & 0.22 & 0.06 & Fair & Chance \\
\hline \multirow{2}{*}{$\begin{array}{l}\text { Yellow- } \\
\text { poplar }\end{array}$} & \multirow{2}{*}{ Prime } & Diameter & 0.64 & $<0.01$ & Substantial & Not by Chance \\
\hline & & Grade & 0.59 & $<0.01$ & Moderate & Not by Chance \\
\hline \multirow{2}{*}{$\begin{array}{l}\text { Yellow- } \\
\text { poplar }\end{array}$} & \multirow{2}{*}{$\begin{array}{c}\text { Grade } 1 \\
\text { Small } \\
\text { Nov }\end{array}$} & Diameter & 0.57 & $<0.01$ & Substantial & Not by Chance \\
\hline & & Grade & 0.52 & $<0.01$ & Substantial & Not by Chance \\
\hline \multirow{2}{*}{$\begin{array}{l}\text { Yellow- } \\
\text { poplar }\end{array}$} & \multirow{2}{*}{$\begin{array}{c}\text { Grade } 1 \\
\text { Small } \\
\text { Jan }\end{array}$} & Diameter & 0.41 & $<0.01$ & Moderate & Not by Chance \\
\hline & & Grade & 0.41 & $<0.01$ & Moderate & Not by Chance \\
\hline \multirow{2}{*}{$\begin{array}{l}\text { Yellow- } \\
\text { poplar }\end{array}$} & \multirow{2}{*}{$\begin{array}{c}\text { Grade } 1 \\
\text { Large }\end{array}$} & Diameter & 0.64 & $<0.01$ & Substantial & Not by Chance \\
\hline & & Grade & 0.12 & $<0.01$ & Slight & Not by Chance \\
\hline \multirow{2}{*}{$\begin{array}{l}\text { Yellow- } \\
\text { poplar }\end{array}$} & \multirow{2}{*}{$\begin{array}{c}\text { Grade } 2 \\
\text { Small }\end{array}$} & Diameter & 0.41 & $<0.01$ & Moderate & Not by Chance \\
\hline & & Grade & 0.09 & 0.15 & Slight & Chance \\
\hline \multirow{2}{*}{$\begin{array}{l}\text { Yellow- } \\
\text { poplar }\end{array}$} & \multirow{2}{*}{$\begin{array}{c}\text { Grade } 2 \\
\text { Large }\end{array}$} & Diameter & 0.36 & 0.02 & Fair & Not by Chance \\
\hline & & Grade & 0.09 & 0.20 & Slight & Chance \\
\hline \multirow{2}{*}{ Soft Maple } & \multirow{2}{*}{ Prime } & Diameter & 0.61 & $<0.01$ & Substantial & Not by Chance \\
\hline & & Grade & 0.30 & 0.02 & Fair & Not by Chance \\
\hline \multirow{2}{*}{ Soft Maple } & \multirow{2}{*}{$\begin{array}{c}\text { Grade } 1 \\
\text { Small }\end{array}$} & Diameter & 0.68 & $<0.01$ & Substantial & Not by Chance \\
\hline & & Grade & 0.46 & $<0.01$ & Moderate & Not by Chance \\
\hline \multirow{2}{*}{ Soft Maple } & \multirow{2}{*}{$\begin{array}{c}\text { Grade } 1 \\
\text { Large }\end{array}$} & Diameter & 0.56 & $<0.01$ & Moderate & Not by Chance \\
\hline & & Grade & 0.01 & 0.89 & Slight & Chance \\
\hline \multirow{2}{*}{ Cherry } & \multirow{2}{*}{$\begin{array}{c}\text { Grade } 1 \\
\text { Small }\end{array}$} & Diameter & 0.69 & $<0.01$ & Substantial & Not by Chance \\
\hline & & Grade & 0.51 & $<0.01$ & Moderate & Not by Chance \\
\hline \multirow{2}{*}{ Cherry } & \multirow{2}{*}{$\begin{array}{c}\text { Grade } 2 \\
\text { Small }\end{array}$} & Diameter & 0.46 & $<0.01$ & Moderate & Not by Chance \\
\hline & & Grade & 0.18 & $<0.01$ & Slight & Not by Chance \\
\hline
\end{tabular}




\section{Analysis of Batch Lumber Yields}

\section{Normality Results}

When testing normality, all batch and lumber grade combinations are a separate distribution. In the Prime grade, for example, there are three batch studies and three lumber grade categories. Therefore, there are nine different distributions to test for normality in the Prime log grade. The use of nonparametric statistics is recommended when $20 \%$ or more of the distributions are nonparametric (I. Holaskova, personal communication, April 9, 2020).

In the Prime grade, only one of nine distributions (11.1\%) was not normally distributed. For Grade 1 small diameter, six of fifteen distributions (40\%) were nonparametric. For both Grade 1 large diameter grade and Grade 2 small diameter, four of the nine distributions (44.4\%) were nonparametric. Finally, for Grade 2 large diameter, two of six distributions (33.3\%) were nonparametric.

Parametric statistics could have been used for the Prime grade lumber yield analysis, but nonparametric statistics were needed for the other four batch types. Instead of mixing parametric and nonparametric statistics for the lumber yield analysis, all lumber yields were analyzed using the nonparametric Wilcoxon test and KruskalWallis tests.

\section{Prime Grade}

No statistically significant differences were noted between batches in any lumber grade. For the One Face and Better lumber grade yields, the mean yield per batch consisted of Red Oak (RO) with a mean yield of $54.5 \%$, Soft Maple (SM) with a mean 
yield of 53.5\%, and Yellow-poplar (YP) with a mean yield of 59.4\%. The Kruskal-Wallis test generated a test statistic of 1.35 and a p-value of 0.51 , indicating that no mean differences existed between the three batches. Pairwise comparisons showed no statistical differences between any of the batches.

For the 1 Common lumber grade yield, RO had a mean yield of $23.2 \%$, SM had a yield of $20.8 \%$, and YP had a yield of $17.8 \%$. The Kruskal-Wallis test statistic was 2.09, with a p-value of 0.35 suggesting that no significant differences existed between batches for this lumber grade.

For the 2 Common and below plus cants, RO yielded of $22.3 \%$, SM yielded $25.7 \%$, and YP yielded 22.8\%. The Kruskal-Wallis test produced a test statistic of 2.27, with an associated $p$-value of 0.32 . Again, no statistically significant differences existed for the yields by species in this lumber grade.

\section{Grade 1 Small Diameter}

For this log grade, five batch studies were completed: Red Oak, Soft Maple, Cherry, and two Yellow-poplar batches. The Yellow-poplar batches were identified by the month they were completed.

For the One Face and Better lumber grade, the yields follow; Red Oak (RO) 32.1\%, Cherry (CH) 37.0\%, Soft Maple (SM) 20.5\%, Yellow-poplar November (YP NOV) $30.4 \%$, Yellow-poplar January (YP JAN) $40.0 \%$. The Kruskal-Wallis test produced a test statistic of 13.45 and a p-value of 0.0093 . Additionally, pairwise comparisons identified several statistically significant differences between batches. Specifically, Soft Maple yield was significantly different from all other batches. Also, Yellow-poplar 
November and Yellow-poplar January were statistically different from each other ( $p$ value of 0.0488 ).

For the 1 Common lumber grade, the mean yields follow: $\mathrm{RO} 23.6 \%, \mathrm{CH} 30.0 \%$, SM 21.8\%, YP NOV 22.5\%, and YP JAN 16.0\%. The Kruskal-Wallis test produced a test statistic of 11.33 , which equates to a p-value of 0.0231 . Pairwise comparisons show that the yield from YP JAN was statistically different from RO ( $p$-value of 0.0446 ) and $\mathrm{CH}$ (p-value of 0.0006$)$.

Yields for the 2 Common and below plus cants follow: RO 44.3\%, CH 33.0\%, SM $57.7 \%$, YP NOV 47.1\%, and YP JAN 44.0\%. The Kruskal-Wallis test produced a test statistic of 19.08 , with a p-value of 0.0008 . Pairwise comparisons indicated that $\mathrm{CH}$ yield was statistically different from all other batches in the grade 1 small diameter category.

\section{Grade 1 Large Diameter}

Three batch studies were completed in this log grade. Each batch was composed of a different species, with Red Oak, Soft Maple, and Yellow-poplar being tested. Each batch contained 25 logs.

For the One Face and Better lumber grade, the mean yields by species were: Red Oak 34.3\%, Soft Maple 48.8\%, and Yellow-poplar 50.7\%. The Kruskal-Wallis test produced a test statistic of 9.09 , with a p-value of 0.0106 . Pairwise comparisons show that Red Oak yield was statistically different from Soft Maple ( $p$-value of 0.0199) and Yellow-poplar ( $p$-value of 0.0056).

For the 1 common lumber grade, the mean yields by species were: Red Oak 27.8\%, Soft Maple 18.0\%, and Yellow-poplar 17.8\%. The Kruskal-Wallis test produced 
a test statistic of 4.77 , with a $p$-value of 0.0921 . This indicates that the yields between batches were not statistically different from each other. Pairwise comparisons again showed that there were no statistically significant differences.

For the 2 Common and below and cant grade, the mean yields by species were: Red Oak 37.9\%, Soft Maple 33.2\%, and Yellow-poplar 31.5\%. The Kruskal-Wallis test produced a test statistic of 1.59 with a p-value of 0.4508 , which again indicates that no batch yields were statistically different in this lumber grade.

\section{Grade 2 Small Diameter}

Three batch studies were completed in this log grade, with each representing a different species. The three species were Cherry, Red Oak, and Yellow-poplar. Each batch contained 25 logs.

For the One Face and Better lumber grade, the yields were: Cherry $20.4 \%$, Red Oak 8.7\%, and Yellow-poplar 16.9\%. The Kruskal-Wallis test produced a test statistic of 7.4493 , with a p-value of 0.0241 . Pairwise comparisons show a statistically significant difference between Red Oak and Cherry ( $p$-value of 0.0049).

For the 1 Common lumber grade, the yields were: Cherry $30.6 \%$, Red Oak $21.6 \%$, and Yellow-poplar 22.1\%. The Kruskal-Wallis test generated a test statistic of 5.2243 , with a p-value of 0.0734 . Pairwise comparisons indicate that a statistically significant difference exists between the Yellow-poplar and Cherry yield ( $p$-value of 0.0457).

For the 2 Common and below plus cants, the yields were: Cherry $49.0 \%$, Red Oak 69.7\%, and Yellow-poplar 61.0\%. The Kruskal-Wallis test generated a test statistic 
of 16.4217 , with a p-value of 0.0003 . Pairwise comparisons show that Cherry yield is significantly different from Red Oak ( $p$-value of $<0.0001$ ) and Yellow-poplar ( $p$-value of $0.0313)$.

\section{Grade 2 Large Diameter}

For this log grade, two batches were tested. One batch was Red Oak and the second was Yellow-poplar. Each batch contained 25 logs. It is important to note that the Red Oak batch was improperly selected. Logs in this grade should be 16" and larger with two clear faces. Overall, 15 out of 25 logs in this batch (60\%) were 15 " or smaller and should not have been included in this batch.

For the One Face and Better lumber grade, the yields were: Red Oak $16.0 \%$ and Yellow-poplar $15.3 \%$. The Wilcoxon test generated a test statistic of 0.1443 with a pvalue of 0.7040 . No statistically significant differences existed in lumber yields between the two batches.

For the 1 Common lumber grade, the yields were: Red Oak $27.4 \%$ and Yellowpoplar $36.7 \%$. The Wilcoxon test produced a test statistic of 4.3506 with a p-value of 0.0370. This indicates that the yields between the two batches were statistically different from each other.

For the 2 Common and below plus cants, the yields were: Red Oak $56.6 \%$ and Yellow-poplar 48.0\%. The Wilcoxon test generated a test statistic of 1.9517 with a pvalue of 0.1624 . This indicates that the yields between the two species were not statistically different. 


\section{Comparison of Lumber Grade Yields between Batch and Individual Log Methods}

For this analysis, the nonparametric Wilcoxon test was used to determine if statistically significant differences existed in lumber grade yields between the batch method and the individual log method. All distributions were tested for normality and found to be non-normal, so the Wilcoxon test was used since it is a nonparametric method. For the individual log method, only logs that belonged in the batch were included. For example, in the Red Oak Grade 2 small diameter batch, only 10 of the 25 logs in the batch were actually grade 2 small diameter logs based on the individual log scaling and grading methodology as shown in Figure 14. For this study, the lumber

yields of the 25 logs in the batch were compared against the 10 logs that truly belonged in the batch. This provided an indication of how batch lumber grade yields were impacted by logs that did not belong in the batch. Tables 2,3 , and 4 provides a comparison of lumber yields, by grade, between the two methods. 
Table 2. One Face and Better Lumber Yields for the Batch and Individual Log Methods.

\begin{tabular}{|c|c|c|c|c|c|c|}
\hline Species & Log Grade & Method & $\mathrm{n}$ & Yield & $\begin{array}{c}\text { Chi- } \\
\text { Square }\end{array}$ & $\mathrm{p}$-value \\
\hline \multirow{2}{*}{ Red Oak } & \multirow{2}{*}{ Prime } & Batch & 20 & $54.5 \%$ & \multirow{2}{*}{0.23} & \multirow{2}{*}{0.63} \\
\hline & & Individual & 16 & $52.7 \%$ & & \\
\hline \multirow{2}{*}{ Red Oak } & \multirow{2}{*}{ Grade 1 Small } & Batch & 25 & $32.0 \%$ & \multirow{2}{*}{0.06} & \multirow{2}{*}{0.81} \\
\hline & & Individual & 24 & $31.0 \%$ & & \\
\hline \multirow{2}{*}{ Red Oak } & \multirow{2}{*}{ Grade 1 Large } & Batch & 25 & $34.3 \%$ & \multirow{2}{*}{0.04} & \multirow{2}{*}{0.84} \\
\hline & & Individual & 11 & $32.3 \%$ & & \\
\hline \multirow{2}{*}{ Red Oak } & \multirow{2}{*}{ Grade 2 Small } & Batch & 25 & $8.7 \%$ & \multirow{2}{*}{0.34} & \multirow{2}{*}{0.56} \\
\hline & & Individual & 10 & $11.1 \%$ & & \\
\hline \multirow{2}{*}{ Red Oak } & \multirow{2}{*}{ Grade 2 Large } & Batch & 25 & $16.0 \%$ & \multirow{2}{*}{0.82} & \multirow{2}{*}{0.37} \\
\hline & & Individual & 8 & $11.8 \%$ & & \\
\hline \multirow{2}{*}{ Yellow-poplar } & \multirow{2}{*}{ Prime } & Batch & 20 & $59.4 \%$ & \multirow{2}{*}{$<.01$} & \multirow{2}{*}{0.98} \\
\hline & & Individual & 18 & $59.4 \%$ & & \\
\hline \multirow{2}{*}{ Yellow-poplar } & \multirow{2}{*}{$\begin{array}{c}\text { Grade } 1 \text { Small } \\
\text { November }\end{array}$} & Batch & 25 & $30.4 \%$ & \multirow{2}{*}{0.16} & \multirow{2}{*}{0.69} \\
\hline & & Individual & 23 & $32.3 \%$ & & \\
\hline \multirow{2}{*}{ Yellow-poplar } & Grade 1 Small & Batch & 25 & $39.7 \%$ & $<01$ & 098 \\
\hline & & Individual & 24 & $39.6 \%$ & & 0.50 \\
\hline Yollousnonlar & Grade 11 arao & Batch & 24 & $50.7 \%$ & & 076 \\
\hline reinow-popial & Gidae I Lalge & Individual & 8 & $48.3 \%$ & 0.05 & 0.10 \\
\hline Yollowenonlar & Grade 2 Small & Batch & 25 & $16.9 \%$ & 006 & 01 \\
\hline rellow-popiar & Grace 2 Sman & Individual & 12 & $11.3 \%$ & 0.00 & 0.01 \\
\hline Yellow-nonlar & Grade 2 I aroe & Batch & 25 & $15.3 \%$ & 001 & ר? \\
\hline retrow-puplat & OIdae 2 Lalge & Individual & 11 & $15.2 \%$ & & 0.52 \\
\hline Soft Manle & Prime & Batch & 20 & $53.5 \%$ & 024 & 062 \\
\hline & & Individual & 14 & $51.4 \%$ & & \\
\hline Soft Manle & Grade 1 small & Batch & 25 & $20.5 \%$ & 048 & 0.49 \\
\hline & & Individual & 18 & $24.6 \%$ & & \\
\hline Soft Manle & Grade 11 arge & Batch & 25 & $18.0 \%$ & 145 & 023 \\
\hline sorividple & Gidae I Lalge & Individual & 10 & $20.8 \%$ & & \\
\hline Cherry & Grade $1 \mathrm{Small}$ & Batch & 25 & $37.0 \%$ & 013 & 071 \\
\hline Cाгену & 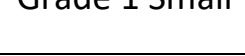 & Individual & 20 & $38.7 \%$ & 0.13 & 0.11 \\
\hline Cherry & Grade 2 Small & Batch & 25 & $20.4 \%$ & 012 & 073 \\
\hline cnerry & Grade 2 smail & Individual & 10 & $18.7 \%$ & 0.12 & 0.13 \\
\hline
\end{tabular}


Table 3. One Common Lumber Yields for the Batch and Individual Log Methods.

\begin{tabular}{|c|c|c|c|c|c|c|}
\hline Species & Log Grade & Method & $\mathrm{n}$ & Yield & $\begin{array}{c}\text { Chi- } \\
\text { Square }\end{array}$ & $\mathrm{p}$-value \\
\hline \multirow{2}{*}{ Red Oak } & \multirow{2}{*}{ Prime } & Batch & 20 & $23.2 \%$ & \multirow{2}{*}{0.12} & \multirow{2}{*}{0.73} \\
\hline & & Individual & 16 & $24.6 \%$ & & \\
\hline \multirow{2}{*}{ Red Oak } & \multirow{2}{*}{ Grade 1 Small } & Batch & 25 & $23.6 \%$ & \multirow{2}{*}{0.01} & \multirow{2}{*}{0.94} \\
\hline & & Individual & 24 & $23.9 \%$ & & \\
\hline \multirow{2}{*}{ Red Oak } & \multirow{2}{*}{ Grade 1 Large } & Batch & 25 & $27.8 \%$ & \multirow{2}{*}{0.23} & \multirow{2}{*}{0.63} \\
\hline & & Individual & 11 & $28.7 \%$ & & \\
\hline \multirow{2}{*}{ Red Oak } & \multirow{2}{*}{ Grade 2 Small } & Batch & 25 & $21.6 \%$ & \multirow{2}{*}{0.28} & \multirow{2}{*}{0.60} \\
\hline & & Individual & 10 & $23.7 \%$ & & \\
\hline \multirow{2}{*}{ Red Oak } & \multirow{2}{*}{ Grade 2 Large } & Batch & 25 & $27.4 \%$ & \multirow{2}{*}{0.09} & \multirow{2}{*}{0.77} \\
\hline & & Individual & 8 & $26.8 \%$ & & \\
\hline \multirow{2}{*}{ Yellow-poplar } & \multirow{2}{*}{ Prime } & Batch & 20 & $17.7 \%$ & \multirow{2}{*}{0.01} & \multirow{2}{*}{0.91} \\
\hline & & Individual & 18 & $17.6 \%$ & & \\
\hline \multirow{2}{*}{ Yellow-poplar } & \multirow{2}{*}{$\begin{array}{c}\text { Grade } 1 \text { Small } \\
\text { November }\end{array}$} & Batch & 25 & $22.5 \%$ & \multirow{2}{*}{0.14} & \multirow{2}{*}{0.71} \\
\hline & & Individual & 23 & $21.0 \%$ & & \\
\hline \multirow{2}{*}{ Yellow-poplar } & Grade 1 Small & Batch & 25 & $16.0 \%$ & 000 & 100 \\
\hline & & Individual & 24 & $16.0 \%$ & & \\
\hline Yellow-nonlar & Grade 1 I aroe & Batch & 24 & $17.8 \%$ & 015 & 070 \\
\hline & & Individual & 8 & $17.3 \%$ & & \\
\hline Yellow-nonlar & Grade 2 Small & Batch & 25 & $22.1 \%$ & 233 & 013 \\
\hline & & Individual & 12 & $29.1 \%$ & & \\
\hline Yollow-nonlar & Grade 2 I aroe & Batch & 25 & $36.7 \%$ & 003 & 086 \\
\hline retrow-pupiat & Ji ace 2 Laige & Individual & 11 & $36.4 \%$ & $0.0 \mathrm{~s}$ & 0.00 \\
\hline Soft Maple & Prime & Batch & 20 & $20.8 \%$ & 0.18 & 0.67 \\
\hline & & Individual & 14 & $22.1 \%$ & & \\
\hline Soft Manle & Grade 1 Small & Batch & 25 & $21.8 \%$ & 057 & 0.45 \\
\hline SOIt iviapte & Gave I Jillán & Individual & 18 & $16.9 \%$ & ( & $0.4 J$ \\
\hline Soft Manle & Grade 1। aroe & Batch & 25 & $18.0 \%$ & 065 & 0.42 \\
\hline Solt iviapte & Ma da 1 Lalge & Individual & 10 & $20.8 \%$ & 0.05 & 0.42 \\
\hline Cherry & Grade 1 small & Batch & 25 & $29.6 \%$ & 0.8 & 078 \\
\hline criemry & Gráe I Small & Individual & 20 & $27.7 \%$ & 0.00 & 0.10 \\
\hline Cherry & Grade $2 \mathrm{~S}$ & Batch & 25 & $30.6 \%$ & 105 & 031 \\
\hline cherry & Grade 2 sma & Individual & 10 & $36.1 \%$ & 1.05 & 0.31 \\
\hline
\end{tabular}


Table 4. Two Common and Lower Lumber and Cant Yields for the Batch and Individual Log Methods.

\begin{tabular}{|c|c|c|c|c|c|c|}
\hline Species & Log Grade & Method & $\mathrm{n}$ & Yield & $\begin{array}{l}\text { Chi- } \\
\text { Square }\end{array}$ & $p$-value \\
\hline \multirow{2}{*}{ Red Oak } & \multirow{2}{*}{ Prime } & Batch & 20 & $22.3 \%$ & \multirow{2}{*}{0.08} & \multirow{2}{*}{0.77} \\
\hline & & Individual & 16 & $22.7 \%$ & & \\
\hline \multirow{2}{*}{ Red Oak } & \multirow{2}{*}{ Grade 1 Small } & Batch & 25 & $44.4 \%$ & \multirow{2}{*}{0.06} & \multirow{2}{*}{0.81} \\
\hline & & Individual & 24 & $45.2 \%$ & & \\
\hline \multirow{2}{*}{ Red Oak } & \multirow{2}{*}{ Grade 1 Large } & Batch & 25 & $37.9 \%$ & \multirow{2}{*}{0.20} & \multirow{2}{*}{0.66} \\
\hline & & Individual & 11 & $39.0 \%$ & & \\
\hline \multirow{2}{*}{ Red Oak } & \multirow{2}{*}{ Grade 2 Small } & Batch & 25 & $69.6 \%$ & \multirow{2}{*}{0.97} & \multirow{2}{*}{0.32} \\
\hline & & Individual & 10 & $65.2 \%$ & & \\
\hline \multirow{2}{*}{ Red Oak } & \multirow{2}{*}{ Grade 2 Large } & Batch & 25 & $56.6 \%$ & \multirow{2}{*}{0.25} & \multirow{2}{*}{0.61} \\
\hline & & Individual & 8 & $61.4 \%$ & & \\
\hline \multirow{2}{*}{ Yellow-poplar } & \multirow{2}{*}{ Prime } & Batch & 20 & $22.9 \%$ & \multirow{2}{*}{0.00} & \multirow{2}{*}{1.00} \\
\hline & & Individual & 18 & $23.1 \%$ & & \\
\hline \multirow{2}{*}{ Yellow-poplar } & \multirow{2}{*}{$\begin{array}{c}\text { Grade } 1 \text { Small } \\
\text { November }\end{array}$} & Batch & 25 & $47.1 \%$ & \multirow{2}{*}{$<.01$} & \multirow{2}{*}{0.97} \\
\hline & & Individual & 23 & $46.7 \%$ & & \\
\hline \multirow{2}{*}{ Yellow-poplar } & Grade 1 Small & Batch & 25 & $44.3 \%$ & $<01$ & 0.98 \\
\hline & & Individual & 24 & $44.4 \%$ & & \\
\hline Yellow-poplar & Grade 1 Large & Batch & 24 & $31.5 \%$ & 0.09 & 0.76 \\
\hline 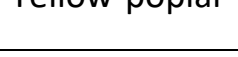 & Gianc t Laige & Individual & 8 & $34.4 \%$ & & \\
\hline Yellow-nonlar & Grade 2 Small & Batch & 25 & $60.9 \%$ & 000 & 100 \\
\hline & 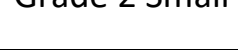 & Individual & 12 & $59.6 \%$ & & \\
\hline Yellow-nonlar & Grade 2 Large & Batch & 25 & $47.9 \%$ & 003 & 086 \\
\hline & & Individual & 11 & $48.3 \%$ & & \\
\hline Soft Maple & Prime & Batch & 20 & $25.8 \%$ & 0.06 & 0.81 \\
\hline & & Individual & 14 & $24.6 \%$ & & \\
\hline Soft Maple & Grade 1 Small & Batch & 25 & $57.7 \%$ & $<.01$ & 0.99 \\
\hline & & Individual & 18 & $58.6 \%$ & & \\
\hline Soft Maple & Grade 1 Large & Batch & 25 & $33.2 \%$ & 0.77 & 0.38 \\
\hline & & Individual & 10 & $35.9 \%$ & & \\
\hline Cherry & Grade 1 Small & Batch & 25 & $33.4 \%$ & 0,01 & 093 \\
\hline 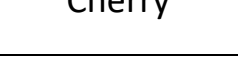 & Giane 1 Jillan & Individual & 20 & $33.6 \%$ & 0.01 & 0.53 \\
\hline Cherry & Grade ? & Batch & 25 & $49.0 \%$ & 030 & 058 \\
\hline cnerry & Grade 2 small & Individual & 10 & $45.2 \%$ & 0.30 & 0.58 \\
\hline
\end{tabular}




\section{Batch Overrun Analysis}

\section{Normality Results}

Before analyzing overrun data, it was necessary to determine if the data was normally distributed. If the data was normally distributed, a one-way ANOVA could be used to determine overrun differences between batches. If the data was not normal, the nonparametric Kruskal-Wallis test would be utilized.

For the Prime grade, one of the three (33\%) distributions was nonparametric. Two out of five (40\%) of the overrun distributions in the Grade 1 small diameter log grade were nonparametric. One of three (33\%) of the distributions in the Grade 1 large diameter batch was nonparametric. For the Grade 2 small diameter and Grade 2 large diameter log grades, all distributions were normally distributed.

For consistency, it was decided that the nonparametric Kruskal-Wallis test would be used to compare mean overrun between batches, even though a One-way ANOVA could have been used for both Grade 2 small and large diameters.

\section{Prime Grade}

For the Prime log grade, three batches were tested. Mean overrun follows: Red Oak 24.8\%, Soft Maple 22.8\%, and Yellow-poplar 23.4\%. The Kruskal-Wallis test generated a test statistic of 1.1992 , with a p-value of 0.5490 indicating that there were no statistically significant differences in overrun between the three batches. Pairwise comparisons also found no statistical differences between batches. 


\section{Grade 1 Small Diameter}

Five batches were tested for the Grade 1 small diameter log grade. Cherry overrun was 44.9\%, Red Oak was 51.5\%, and Soft Maple was 66.9\%, Yellow-poplar November was 55.0\%, and Yellow-poplar January was 48.7\%. The Kruskal-Wallis test produced a test statistic of 17.9193 , with a p-value of 0.0013 . Pairwise comparisons showed that the Soft Maple overrun was statistically different from all other batches.

\section{Grade 1 Large Diameter}

Three batches were tested for the Grade 1 Large Diameter log grade. Red Oak overrun was $27.9 \%$, Soft Maple was $43.4 \%$, and Yellow-poplar was $28.2 \%$. The Kruskal-Wallis test produced a test statistic of 6.2156 with a p-value of 0.0447 . Pairwise comparisons show that Soft Maple overrun was statistically different from both Red Oak (p-value of 0.0270$)$ and Yellow-poplar (p-value of 0.0394).

\section{Grade 2 Small Diameter}

Three batches were tested for the Grade 2 small diameter log grade. Overrun in Cherry was $42.2 \%$, Red Oak 58.2\%, and Yellow-poplar 54.5\%. The Kruskal-Wallis test produced a test statistic of 5.1582 , with a p-value of 0.0758 . Pairwise comparisons found one statistically significant difference between Yellow-poplar and Cherry ( $p$-value of 0.0270$)$.

\section{Grade 2 Large Diameter}

Two batches were tested for the Grade 2 large diameter log grade. Overrun for Red Oak was $47.2 \%$ and overrun for Yellow-poplar was 29.5\%. The Wilcoxon test 
produced a test statistic of 7.4327 with a p-value of 0.0064 indicating that the mean overrun between the two batches was statistically different.

However, the Red Oak batch was improperly selected by the participating sawmill. 15 of the 25 logs (60\%) were either 14 " or 15 " diameter logs. This would account for the statistical difference between the mean overruns, as higher overrun is to be expected with smaller diameter logs.

\section{Comparison of Overrun between Batch and Individual Log Methods}

Overrun results between the two methods were tested to determine if the methods resulted in statistically significant differences in overrun. This analysis provided insight into the differences in overrun that occurred between the two methods. Three main components could affect the overrun results between the two methods; rolling or not rolling the log, differences in scaling deductions caused by log defects, and accuracy of diameter measurements. This analysis could not determine which of the three components caused the differences in overrun but is useful in determining the consistency of overrun results between the batch study and individual log study methods.

Two different analyses were conducted, depending on whether the data were normally distributed or nonparametric. Normally distributed data were analyzed using ttesting, while nonparametric tests were analyzed using the Wilcoxon test. Table 5 provides results for batches with nonparametric overrun data, and batches with normally distributed overrun data are presented in Table 6. 
Table 5. Differences in Overrun between the Batch Mill Study and Individual Log Mill Study Methods using the Wilcoxon nonparametric test.

\begin{tabular}{|c|c|c|c|c|c|c|}
\hline Species & Log Grade & Method & $\mathrm{n}$ & Yield & Chi-square & $\mathrm{p}$-value \\
\hline \multirow{2}{*}{ Red Oak } & \multirow{2}{*}{ Grade 1 Small } & Batch & 25 & $46.5 \%$ & \multirow{2}{*}{0.59} & \multirow{2}{*}{0.44} \\
\hline & & Individual & 25 & $51.5 \%$ & & \\
\hline \multirow{2}{*}{ Red Oak } & \multirow{2}{*}{ Grade 2 Small } & Batch & 25 & $57.1 \%$ & \multirow{2}{*}{0.09} & \multirow{2}{*}{0.76} \\
\hline & & Individual & 25 & $58.2 \%$ & & \\
\hline \multirow{2}{*}{ Yellow-poplar } & \multirow{2}{*}{ Prime } & Batch & 20 & $26.3 \%$ & \multirow{2}{*}{0.01} & \multirow{2}{*}{0.90} \\
\hline & & Individual & 20 & $23.4 \%$ & & \\
\hline \multirow{2}{*}{ Yellow-poplar } & \multirow{2}{*}{$\begin{array}{c}\text { Grade } 1 \text { Small } \\
\text { January }\end{array}$} & Batch & 25 & $37.8 \%$ & \multirow{2}{*}{7.17} & \multirow{2}{*}{0.01} \\
\hline & & Individual & 25 & $48.7 \%$ & & \\
\hline \multirow{2}{*}{ Yellow-poplar } & \multirow{2}{*}{ Grade 2 Large } & Batch & 25 & $17.6 \%$ & \multirow{2}{*}{4.35} & \multirow{2}{*}{0.04} \\
\hline & & Individual & 25 & $29.5 \%$ & & \\
\hline
\end{tabular}


Table 6. Differences in Overrun between the Batch Mill Study and Individual Log Mill Study Methods using Student's t-test for normally distributed data.

\begin{tabular}{|c|c|c|c|c|c|c|}
\hline Species & Log Grade & Method & $\mathrm{n}$ & Yield & $\mathrm{t}$ & $\mathrm{p}$-value \\
\hline \multirow{2}{*}{ Red Oak } & \multirow{2}{*}{ Prime } & Batch & 20 & $25.7 \%$ & \multirow{2}{*}{-0.26} & \multirow{2}{*}{0.79} \\
\hline & & Individual & 20 & $24.8 \%$ & & \\
\hline \multirow{2}{*}{ Red Oak } & \multirow{2}{*}{ Grade 1 Large } & Batch & 25 & $27.4 \%$ & \multirow{2}{*}{0.14} & \multirow{2}{*}{0.89} \\
\hline & & Individual & 25 & $27.9 \%$ & & \\
\hline \multirow{2}{*}{ Red Oak } & \multirow{2}{*}{ Grade 2 Large } & Batch & 25 & $39.4 \%$ & \multirow{2}{*}{1.45} & \multirow{2}{*}{0.15} \\
\hline & & Individual & 25 & $47.2 \%$ & & \\
\hline \multirow{2}{*}{ Yellow-poplar } & \multirow{2}{*}{$\begin{array}{c}\text { Grade } 1 \text { Small } \\
\text { November }\end{array}$} & Batch & 25 & $47.2 \%$ & \multirow{2}{*}{1.82} & \multirow{2}{*}{0.07} \\
\hline & & Individual & 25 & $55.0 \%$ & & \\
\hline \multirow{2}{*}{ Yellow-poplar } & \multirow{2}{*}{ Grade 1 Large } & Batch & 24 & $24.8 \%$ & \multirow{2}{*}{0.93} & \multirow{2}{*}{0.36} \\
\hline & & Individual & 24 & $28.2 \%$ & & \\
\hline \multirow{2}{*}{ Yellow-poplar } & \multirow{2}{*}{ Grade 2 Small } & Batch & 25 & $52.1 \%$ & \multirow{2}{*}{0.40} & \multirow{2}{*}{0.69} \\
\hline & & Individual & 25 & $54.5 \%$ & & \\
\hline \multirow{2}{*}{ Soft Maple } & \multirow{2}{*}{ Prime } & Batch & 20 & $21.5 \%$ & \multirow{2}{*}{0.28} & \multirow{2}{*}{0.78} \\
\hline & & Individual & 20 & $22.8 \%$ & & \\
\hline \multirow{2}{*}{ Soft Maple } & \multirow{2}{*}{ Grade 1 Small } & Batch & 25 & $59.1 \%$ & \multirow{2}{*}{1.14} & \multirow{2}{*}{0.29} \\
\hline & & Individual & 25 & $66.9 \%$ & & \\
\hline \multirow{2}{*}{ Soft Maple } & \multirow{2}{*}{ Grade 1 Large } & Batch & 25 & $30.0 \%$ & 247 & 0.12 \\
\hline & & Individual & 25 & $43.4 \%$ & & \\
\hline Chorrut & $\mathrm{Crado} 1 \mathrm{cmall}$ & Batch & 25 & $44.5 \%$ & م00 & 200 \\
\hline (ाता ту & 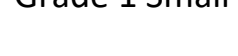 & Individual & 25 & $44.9 \%$ & & \\
\hline Cherry & $\mathrm{Cmadr} 2 \mathrm{cmall}$ & Batch & 25 & $48.4 \%$ & 100 & 070 \\
\hline Cाrenty & Uiace z Jinan & Individual & 25 & $42.2 \%$ & -1.05 & 0.20 \\
\hline
\end{tabular}

From these analyses, only two statistically significant results were found. The January Grade 1 small diameter and Grade 2 large diameter Yellow-poplar batches both showed statistically significant differences in overrun. The November Grade 1 
small diameter Yellow-poplar batch was very close to being significant, with a p-value of 0.07 .

A second overrun analysis was conducted comparing overrun results between the batch study and individual log study methods. For this analysis, the batch overrun results were compared against only the logs in the batch that were correctly graded. Analysis results for the nonparametric overrun distributions are provided in Table 7 , while the results of the parametric overrun distributions are provided in Table 8. An alpha level of 0.05 was used to determine significance.

Table 7. Differences in Overrun between the Batch Mill Study and Correctly Graded Logs according to the Individual Log Study Method using the Wilcoxon non-parametric test.

\begin{tabular}{|c|c|c|c|c|c|c|}
\hline Species & Log Grade & Method & $\mathrm{n}$ & Yield & Chi-square & $p$-value \\
\hline \multirow{2}{*}{ Red Oak } & \multirow{2}{*}{ Grade 1 Small } & Batch & 25 & $46.5 \%$ & \multirow{2}{*}{1.04} & \multirow{2}{*}{0.31} \\
\hline & & Individual & 24 & $52.7 \%$ & & \\
\hline \multirow{2}{*}{ Red Oak } & \multirow{2}{*}{ Grade 2 Small } & Batch & 25 & $57.1 \%$ & \multirow{2}{*}{0.68} & \multirow{2}{*}{0.41} \\
\hline & & Individual & 10 & $64.9 \%$ & & \\
\hline \multirow{2}{*}{ Yellow-poplar } & \multirow{2}{*}{ Prime } & Batch & 20 & $26.3 \%$ & \multirow{2}{*}{$<.01$} & \multirow{2}{*}{0.95} \\
\hline & & Individual & 18 & $23.9 \%$ & & \\
\hline \multirow{2}{*}{ Yellow-poplar } & \multirow{2}{*}{$\begin{array}{c}\text { Grade } 1 \text { Small } \\
\text { January }\end{array}$} & Batch & 25 & $37.8 \%$ & \multirow{2}{*}{7.35} & \multirow{2}{*}{0.01} \\
\hline & & Individual & 24 & $49.2 \%$ & & \\
\hline \multirow{2}{*}{ Yellow-poplar } & \multirow{2}{*}{ Grade 2 Large } & Batch & 25 & $17.6 \%$ & \multirow{2}{*}{0.04} & \multirow{2}{*}{0.85} \\
\hline & & Individual & 11 & $22.1 \%$ & & \\
\hline
\end{tabular}


Table 8. Differences in Overrun between the Batch Mill Study and Correctly Graded Logs according to the Individual Log Study Method using Student's t-test for normally distributed data.

\begin{tabular}{|c|c|c|c|c|c|c|}
\hline Species & Log Grade & Method & $\mathrm{n}$ & Yield & $\mathrm{t}$ & $\mathrm{p}$-value \\
\hline \multirow{2}{*}{ Red Oak } & \multirow{2}{*}{ Prime } & Batch & 20 & $25.7 \%$ & \multirow{2}{*}{0.27} & \multirow{2}{*}{0.79} \\
\hline & & Individual & 16 & $26.7 \%$ & & \\
\hline \multirow{2}{*}{ Red Oak } & \multirow{2}{*}{ Grade 1 Large } & Batch & 25 & $27.4 \%$ & \multirow{2}{*}{0.62} & \multirow{2}{*}{0.54} \\
\hline & & Individual & 11 & $30.4 \%$ & & \\
\hline \multirow{2}{*}{ Red Oak } & \multirow{2}{*}{ Grade 2 Large } & Batch & 25 & $39.4 \%$ & \multirow{2}{*}{1.93} & \multirow{2}{*}{0.06} \\
\hline & & Individual & 8 & $54.3 \%$ & & \\
\hline \multirow{2}{*}{ Yellow-poplar } & \multirow{2}{*}{$\begin{array}{c}\text { Grade } 1 \text { Small } \\
\text { November }\end{array}$} & Batch & 25 & $47.2 \%$ & \multirow{2}{*}{1.52} & \multirow{2}{*}{0.14} \\
\hline & & Individual & 23 & $53.4 \%$ & & \\
\hline \multirow{2}{*}{ Yellow-poplar } & \multirow{2}{*}{ Grade 1 Large } & Batch & 24 & $24.8 \%$ & \multirow{2}{*}{0.75} & \multirow{2}{*}{0.46} \\
\hline & & Individual & 8 & $28.8 \%$ & & \\
\hline \multirow{2}{*}{ Yellow-poplar } & \multirow{2}{*}{ Grade 2 Small } & Batch & 25 & $52.1 \%$ & \multirow{2}{*}{0.78} & \multirow{2}{*}{0.44} \\
\hline & & Individual & 12 & $58.4 \%$ & & \\
\hline \multirow{2}{*}{ Soft Maple } & \multirow{2}{*}{ Prime } & Batch & 20 & $21.5 \%$ & \multirow{2}{*}{-0.49} & \multirow{2}{*}{0.63} \\
\hline & & Individual & 14 & $19.2 \%$ & & \\
\hline \multirow{2}{*}{ Soft Maple } & \multirow{2}{*}{ Grade 1 Small } & Batch & 25 & $59.1 \%$ & \multirow{2}{*}{1.74} & \multirow{2}{*}{0.19} \\
\hline & & Individual & 18 & $69.8 \%$ & & \\
\hline \multirow{2}{*}{ Soft Maple } & \multirow{2}{*}{ Grade 1 Large } & Batch & 25 & $30.0 \%$ & 200 & $005 *$ \\
\hline & & Individual & 10 & $52.6 \%$ & 2.00 & $0.05^{\infty}$ \\
\hline Cherro & Grads $1 \mathrm{cmall}$ & Batch & 25 & $44.5 \%$ & 001 & 097 \\
\hline cherry & Grade 1 Jmall & Individual & 20 & $44.7 \%$ & 0.04 & 0.97 \\
\hline Cherry & Grade 2 Smal & Batch & 25 & $48.4 \%$ & -031 & 076 \\
\hline слиту & 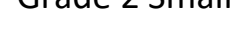 & Individual & 10 & $46.2 \%$ & -0.01 & 0.10 \\
\hline
\end{tabular}

From these analyses, two statistically significant differences were found, along with some batches that were borderline significant. Statistically significant differences were observed in overrun between the two methods for the Grade 1 small diameter January Yellow-poplar batch and for the Soft Maple Grade 1 Large diameter batch. Red Oak Grade 2 large diameter was marginally significant, with a p-value of 0.06 .

\section{Batch Breakeven Analysis}


In the following breakeven analysis, the lumber grade yields, overrun, product pricing, and sawing costs are used to determine a breakeven price for each batch. All Prime grade batches contained 20 logs, while all other log grades contained 25 logs in each batch. The Grade 1 Large diameter Yellow-poplar batch contained 24 logs, as one log contained metal and had to be removed from the study.

\section{Red Oak}

Five batch studies were completed in this species, one each in the Prime Grade, Grade 1 small diameter, Grade 1 large diameter, Grade 2 small diameter, and Grade 2 large diameter categories. The following lumber prices were used: FAS: $\$ 740.00,1 \mathrm{~F}$ : $\$ 740.00,1 \mathrm{C}: \$ 585.00,2 \mathrm{C}: \$ 570.00,3 \mathrm{~A}: \$ 505.00,3 \mathrm{~B}: \$ 282.00$, and Cant: $\$ 470.00$. The sawing cost used for the Red Oak breakeven analysis was $\$ 299.80$. Lumber yield percentages and overrun used for the Red Oak batch breakeven analysis are provided in Table 9.

Table 9. Lumber Grade Yields and Overrun for Red Oak Batch Studies

\begin{tabular}{|l|c|c|c|c|c|c|c|c|c|}
\hline \multirow{2}{*}{\multicolumn{1}{|c|}{ Batch }} & \multicolumn{7}{|c|}{ NHLA Lumber Grades } & & Break \\
\cline { 2 - 10 } & FAS & 1F & \multicolumn{1}{c|}{ 1C } & \multicolumn{1}{c|}{ 3A } & 3B & CANT & Overrun & Even \\
\hline Prime & 0.375 & 0.157 & 0.248 & 0.054 & 0.028 & 0.004 & 0.135 & 0.233 & $\$ 428.94$ \\
\hline Grade 1 Small & 0.160 & 0.173 & 0.232 & 0.063 & 0.033 & 0.037 & 0.301 & 0.437 & $\$ 412.89$ \\
\hline Grade 1 Large & 0.191 & 0.168 & 0.275 & 0.124 & 0.030 & 0.019 & 0.193 & 0.243 & $\$ 383.66$ \\
\hline Grade 2 Small & 0.031 & 0.062 & 0.229 & 0.203 & 0.088 & 0.041 & 0.345 & 0.569 & $\$ 353.83$ \\
\hline Grade 2 Large & 0.043 & 0.119 & 0.306 & 0.168 & 0.058 & 0.064 & 0.245 & 0.384 & $\$ 372.50$ \\
\hline \$MBF & 740.00 & 740.00 & 585.00 & 570.00 & 505.00 & 282.00 & 470.00 & & \\
\hline
\end{tabular}

\section{Yellow-poplar}


Six batch studies were conducted in this species. Two batch studies were conducted for the grade 1 small log grade, while one study each was done for the Prime, grade 1 large, grade 2 small, and grade 2 large log grades. Lumber pricing was as follows: FAS: $\$ 795.00,1 \mathrm{~F}: \$ 795.00,1 \mathrm{C}: \$ 390.00,2 \mathrm{C}: \$ 300.00,3 \mathrm{~B}: \$ 260.00$, and cant: $\$ 470.00$. A sawing cost of $\$ 223.00$ per MBF was used for Yellow-poplar analyses. Lumber yield percentages and overrun information for each batch is provided in Table 10.

Table 10. Lumber Grade Yields and Overrun for Yellow-poplar Batch Studies.

\begin{tabular}{|c|c|c|c|c|c|c|c|c|}
\hline \multirow[b]{2}{*}{ Batch } & \multicolumn{6}{|c|}{ NHLA Lumber Grades } & \multirow[b]{2}{*}{ Overrun } & \multirow[b]{2}{*}{ Break Even } \\
\hline & FAS & $1 \mathrm{~F}$ & $1 C$ & $2 C$ & $3 B$ & CANT & & \\
\hline Prime & 0.404 & 0.187 & 0.182 & 0.079 & 0.015 & 0.134 & 0.208 & $\$ 492.80$ \\
\hline $\begin{array}{l}\text { Grade } 1 \text { Small } \\
\text { NOV }\end{array}$ & 0.163 & 0.158 & 0.224 & 0.121 & 0.018 & 0.317 & 0.455 & $\$ 449.41$ \\
\hline Grade 1 Small JAN & 0.263 & 0.140 & 0.168 & 0.103 & 0.023 & 0.302 & 0.366 & $\$ 467.49$ \\
\hline Grade 1 Large & 0.363 & 0.161 & 0.171 & 0.105 & 0.026 & 0.175 & 0.237 & $\$ 470.12$ \\
\hline Grade 2 Small & 0.070 & 0.097 & 0.230 & 0.380 & 0.010 & 0.212 & 0.485 & $\$ 238.21$ \\
\hline Grade 2 Large & 0.089 & 0.064 & 0.380 & 0.300 & 0.041 & 0.126 & 0.152 & $\$ 320.94$ \\
\hline$\$ / M B F$ & 795.00 & 795.00 & 390.00 & 300.00 & 260.00 & 470.00 & & \\
\hline
\end{tabular}

\section{Soft Maple}

Three batch studies were completed for this species. There was one batch study each for the Prime, Grade 1 small, and Grade 1 large log grades. Both FAS and 1 Common lumber were color sorted in this species, where each grade has a sap and a brown category. Lumber prices follow: FAS-Sap: \$1265.00, FAS-Brown: $\$ 1265.00,1$ CSap: \$815.00, 1C-Brown: $\$ 815.00$, 2C: $\$ 450.00$, 3C: $\$ 256.00$, and Cant: $\$ 476.00$. The sawing cost used was $\$ 265.00$ per MBF. Table 11 provides lumber grade yields and overrun for each of the three batches in this species. 
Table 11. Lumber Grade Yields and Overrun for Soft Maple Batch Studies.

\begin{tabular}{|c|c|c|c|c|c|c|c|c|c|}
\hline \multirow[b]{2}{*}{ Batch } & \multicolumn{7}{|c|}{ NHLA Lumber Grades } & \multirow[b]{2}{*}{ Overrun } & \multirow[b]{2}{*}{$\begin{array}{c}\text { Break } \\
\text { Even }\end{array}$} \\
\hline & $\begin{array}{l}\text { FAS } \\
\text { Sap }\end{array}$ & $\begin{array}{c}\text { FAS } \\
\text { Brown }\end{array}$ & $\begin{array}{l}1 C \\
\text { Sap }\end{array}$ & $\begin{array}{c}1 \mathrm{C} \\
\text { Brown }\end{array}$ & $2 \mathrm{C}$ & $3 C$ & CANT & & \\
\hline Prime & 0.417 & 0.124 & 0.146 & 0.061 & 0.090 & 0.029 & 0.133 & 0.202 & $\$ 840.75$ \\
\hline Grade 1 Small & 0.165 & 0.071 & 0.202 & 0.033 & 0.201 & 0.052 & 0.276 & 0.580 & $\$ 727.66$ \\
\hline Grade 1 Large & 0.382 & 0.098 & 0.130 & 0.049 & 0.121 & 0.034 & 0.186 & 0.271 & $\$ 812.98$ \\
\hline$\$ / M B F$ & 1,265 & 1,265 & 815 & 815 & 450 & 256 & 476 & & \\
\hline
\end{tabular}

\section{Cherry}

Two batch studies were conducted in this species. These batches were for the Grade 1 large and Grade 2 small log grades. FAS lumber was color sorted in this species. FAS lumber was further classified as either FAS-Sap or FAS-Red, depending on color. Lumber prices follow: FAS-Sap: $\$ 960.00$, FAS-Red: $\$ 960.00,1 \mathrm{C}: \$ 465.00$, 2C: $\$ 175.00,3 \mathrm{C}: \$ 175.00$, and Cant: $\$ 450.00$. Table 12 provides lumber yields and overrun as calculated from each batch study.

Table 12. Lumber Grade Yields and Overrun for Cherry Batch Studies.

\begin{tabular}{|c|c|c|c|c|c|c|c|c|}
\hline \multirow[b]{2}{*}{ Batch } & \multicolumn{6}{|c|}{ NHLA Lumber Grades } & \multirow[b]{2}{*}{ Overrun } & \multirow[b]{2}{*}{ Break Even } \\
\hline & $\begin{array}{l}\text { FAS- } \\
\text { Sap }\end{array}$ & FAS-Red & $1 C$ & $2 \mathrm{C}$ & $3 C$ & CANT & & \\
\hline Grade 1 Large & 0.357 & 0.042 & 0.285 & 0.092 & 0.039 & 0.185 & 0.442 & $\$ 521.47$ \\
\hline Grade 2 Small & 0.003 & 0.208 & 0.311 & 0.199 & 0.056 & 0.223 & 0.461 & $\$ 339.00$ \\
\hline$\$ / M B F$ & 960 & 960 & 465 & 175 & 175 & 450 & & \\
\hline
\end{tabular}

\section{Batch Results using AHC Log Grading and Scaling}


The breakeven analysis in the previous section was based entirely on the batch results. That is, the overall grade yields and overrun were for the entire batch, with no way to separate any data based on individual log characteristics. For a basic comparison of the AHMI/AHC batch results with the cooperating mill results, the only difference would result from scaling differences and reflect solely in the overrun results. Tables 13, 14, 15, and 16 show those breakeven pricing differences for each of the 16 batches.

Table 13. Red Oak Batch Study Results using AHC Log Scaling Results.

\begin{tabular}{|l|c|c|c|c|c|c|c|c|c|}
\hline & \multicolumn{7}{|c|}{ NHLA Lumber Grades } & & \\
\cline { 2 - 10 } \multicolumn{1}{|c|}{ Batch } & FAS & $1 \mathrm{~F}$ & 1C & 2A & 3A & 3B & CANT & Overrun & Break Even \\
\hline Prime & 0.375 & 0.157 & 0.248 & 0.054 & 0.028 & 0.004 & 0.135 & 0.225 & $\$ 426.16$ \\
\hline Grade 1 Small & 0.160 & 0.173 & 0.232 & 0.063 & 0.033 & 0.037 & 0.301 & 0.473 & $\$ 423.23$ \\
\hline Grade 1 Large & 0.191 & 0.168 & 0.275 & 0.124 & 0.030 & 0.019 & 0.193 & 0.251 & $\$ 386.13$ \\
\hline Grade 2 Small & 0.031 & 0.062 & 0.229 & 0.203 & 0.088 & 0.041 & 0.345 & 0.572 & $\$ 373.22$ \\
\hline Grade 2 Large & 0.043 & 0.119 & 0.306 & 0.168 & 0.058 & 0.064 & 0.245 & 0.440 & $\$ 368.15$ \\
\hline \$MBF & 740 & 740 & 585 & 570 & 505 & 282 & 470 & & \\
\hline
\end{tabular}

Table 14. Yellow-poplar Batch Study Results using AHC Log Scaling Results.

\begin{tabular}{|c|c|c|c|c|c|c|c|c|}
\hline \multirow[b]{2}{*}{ Batch } & \multicolumn{6}{|c|}{ NHLA Lumber Grades } & \multirow[b]{2}{*}{ Overrun } & \multirow[b]{2}{*}{ Break Even } \\
\hline & FAS & $1 \mathrm{~F}$ & $1 \mathrm{C}$ & $2 \mathrm{C}$ & $3 B$ & CANT & & \\
\hline Prime & 0.404 & 0.187 & 0.182 & 0.079 & 0.015 & 0.134 & 0.207 & $\$ 492.39$ \\
\hline Grade 1 Small NOV & 0.163 & 0.158 & 0.224 & 0.121 & 0.018 & 0.317 & 0.532 & $\$ 473.32$ \\
\hline Grade 1 Small JAN & 0.263 & 0.140 & 0.168 & 0.103 & 0.023 & 0.302 & 0.473 & $\$ 503.92$ \\
\hline Grade 1 Large & 0.363 & 0.161 & 0.171 & 0.105 & 0.026 & 0.175 & 0.260 & $\$ 478.90$ \\
\hline Grade 2 Small & 0.070 & 0.097 & 0.230 & 0.380 & 0.010 & 0.212 & 0.516 & $\$ 327.71$ \\
\hline Grade 2 Large & 0.089 & 0.064 & 0.380 & 0.300 & 0.041 & 0.126 & 0.256 & $\$ 259.63$ \\
\hline$\$ / M B F$ & 795 & 795 & 390 & 300 & 260 & 470 & & \\
\hline
\end{tabular}

Table 15. Soft Maple Batch Study Results using AHC Log Scaling Results. 


\begin{tabular}{|c|c|c|c|c|c|c|c|c|c|}
\hline \multirow[b]{2}{*}{ Batch } & \multicolumn{7}{|c|}{ NHLA Lumber Grades } & \multirow[b]{2}{*}{ Overrun } & \multirow[b]{2}{*}{ Break Even } \\
\hline & $\begin{array}{l}\text { FAS } \\
\text { Sap }\end{array}$ & $\begin{array}{l}\text { FAS } \\
\text { Brown }\end{array}$ & $\begin{array}{l}1 \mathrm{C} \\
\text { Sap }\end{array}$ & $\begin{array}{c}1 \mathrm{C} \\
\text { Brown }\end{array}$ & $2 \mathrm{C}$ & $3 C$ & CANT & & \\
\hline Prime & 0.417 & 0.124 & 0.146 & 0.061 & 0.090 & 0.029 & 0.133 & 0.220 & $\$ 853.34$ \\
\hline Grade 1 Small & 0.165 & 0.071 & 0.202 & 0.033 & 0.201 & 0.052 & 0.276 & 0.643 & $\$ 756.67$ \\
\hline Grade 1 Large & 0.382 & 0.098 & 0.130 & 0.049 & 0.121 & 0.034 & 0.186 & 0.393 & $\$ 891.02$ \\
\hline$\$ / M B F$ & 1,265 & 1,265 & 815 & 815 & 450 & 256 & 476 & & \\
\hline
\end{tabular}

Table 16. Cherry Batch Study Results using AHC Log Scaling Results.

\begin{tabular}{|c|c|c|c|c|c|c|c|c|}
\hline \multirow[b]{2}{*}{ Batch } & \multicolumn{6}{|c|}{ NHLA Lumber Grades } & \multirow[b]{2}{*}{ Overrun } & \multirow[b]{2}{*}{ Break Even } \\
\hline & $\begin{array}{l}\text { FAS- } \\
\text { Sap }\end{array}$ & $\begin{array}{l}\text { FAS- } \\
\text { Red }\end{array}$ & $1 \mathrm{C}$ & $2 C$ & $3 C$ & CANT & & \\
\hline Grade 1 Large & 0.357 & 0.042 & 0.285 & 0.092 & 0.039 & 0.185 & 0.435 & $\$ 518.86$ \\
\hline Grade 2 Small & 0.003 & 0.208 & 0.311 & 0.199 & 0.056 & 0.223 & 0.387 & $\$ 321.83$ \\
\hline$\$ / M B F$ & $\$ 960$ & $\$ 960$ & $\$ 465$ & $\$ 175$ & $\$ 175$ & $\$ 450$ & & \\
\hline
\end{tabular}

Since the batch compositions between the AHMI/AHC individual log method and the mill's batch selection process differed significantly, an additional analysis was completed based solely on the logs that actually belonged in the batch designation. This analysis can provide insights into how breakeven prices are impacted by logs that do not belong in the batch.

Pricing and sawing costs used in this analysis are the same as those used in the batch study breakeven analysis. For each species group, Tables 17 through 20 provide the sample size, lumber yield percentages by lumber grade, overrun, and calculated breakeven prices for both the original batch and only the logs that should have been included in the batch. The range of breakeven price differences calculated as the absolute value of (Mill Batch Breakeven Price - AHMI Batch Breakeven Price) was from a low of $\$ 0.57$ (Prime RO) to a high of $\$ 93.63$ (YP Grade 2 Large Diameter). 


\section{Red Oak}

Table 17. Lumber Yields and Overrun for Revised Red Oak Batches.

\begin{tabular}{|c|c|c|c|c|c|c|c|c|c|c|}
\hline \multirow[b]{2}{*}{ Batch } & \multirow[b]{2}{*}{$\mathrm{n}$} & \multicolumn{7}{|c|}{ NHLA Lumber Grades } & \multirow[b]{2}{*}{ Overrun } & \multirow{2}{*}{$\begin{array}{c}\text { Break } \\
\text { Even }\end{array}$} \\
\hline & & FAS & $1 \mathrm{~F}$ & $1 \mathrm{C}$ & $2 \mathrm{~A}$ & $3 \mathrm{~A}$ & $3 B$ & CANT & & \\
\hline Prime & 16 & 0.381 & 0.139 & 0.258 & 0.052 & 0.029 & 0.004 & 0.136 & 0.244 & $\$ 429.51$ \\
\hline Grade 1 Small & 24 & 0.153 & 0.167 & 0.236 & 0.064 & 0.035 & 0.039 & 0.306 & 0.436 & $\$ 407.87$ \\
\hline Grade 1 Large & 11 & 0.128 & 0.201 & 0.294 & 0.129 & 0.027 & 0.019 & 0.203 & 0.304 & $\$ 395.87$ \\
\hline Grade 2 Small & 10 & 0.042 & 0.081 & 0.252 & 0.181 & 0.040 & 0.039 & 0.364 & 0.637 & $\$ 399.57$ \\
\hline Grade 2 Large & 8 & 0.059 & 0.065 & 0.322 & 0.182 & 0.049 & 0.059 & 0.264 & 0.363 & $\$ 340.11$ \\
\hline
\end{tabular}

\section{Yellow Poplar}

Table 18. Lumber Yields and Overrun for Revised Yellow-poplar Batches.

\begin{tabular}{|c|c|c|c|c|c|c|c|c|c|}
\hline \multirow[b]{2}{*}{ Batch } & \multirow[b]{2}{*}{$\mathrm{n}$} & \multicolumn{6}{|c|}{ NHLA Lumber Grades } & \multirow[b]{2}{*}{ Overrun } & \multirow{2}{*}{$\begin{array}{l}\text { Break } \\
\text { Even }\end{array}$} \\
\hline & & FAS & $1 \mathrm{~F}$ & $1 C$ & $2 \mathrm{C}$ & $3 B$ & CANT & & \\
\hline Prime & 18 & 0.415 & 0.175 & 0.181 & 0.082 & 0.017 & 0.131 & 0.201 & $\$ 489.08$ \\
\hline Grade 1 Small NOV & 23 & 0.173 & 0.173 & 0.203 & 0.110 & 0.020 & 0.321 & 0.458 & $\$ 467.01$ \\
\hline Grade 1 Small JAN & 24 & 0.266 & 0.136 & 0.168 & 0.100 & 0.025 & 0.305 & 0.360 & $\$ 465.07$ \\
\hline Grade 1 Large & 8 & 0.307 & 0.197 & 0.162 & 0.120 & 0.059 & 0.155 & 0.234 & $\$ 450.47$ \\
\hline Grade 2 Small & 12 & 0.041 & 0.086 & 0.295 & 0.364 & 0.004 & 0.210 & 0.446 & $\$ 292.03$ \\
\hline Grade 2 Large & 11 & 0.068 & 0.074 & 0.393 & 0.313 & 0.040 & 0.112 & 0.136 & $\$ 227.31$ \\
\hline
\end{tabular}

\section{Soft Maple}

Table 19. Lumber Yields and Overrun for Revised Soft Maple Batches 


\begin{tabular}{|c|c|c|c|c|c|c|c|c|c|c|}
\hline \multirow[b]{2}{*}{ Batch } & \multirow[b]{2}{*}{$\mathrm{n}$} & \multicolumn{7}{|c|}{ NHLA Lumber Grades } & \multirow[b]{2}{*}{ Overrun } & \multirow[b]{2}{*}{$\begin{array}{c}\text { Break } \\
\text { Even }\end{array}$} \\
\hline & & $\begin{array}{l}\text { FAS } \\
\text { Sap }\end{array}$ & $\begin{array}{l}\text { FAS } \\
\text { Brown }\end{array}$ & $\begin{array}{l}1 C \\
\text { Sap }\end{array}$ & $\begin{array}{c}1 \mathrm{C} \\
\text { Brown }\end{array}$ & $2 \mathrm{C}$ & $3 C$ & CANT & & \\
\hline Prime & 14 & 0.414 & 0.103 & 0.162 & 0.061 & 0.087 & 0.036 & 0.137 & 0.185 & $\$ 810.93$ \\
\hline Grade 1 Small & 18 & 0.178 & 0.097 & 0.152 & 0.021 & 0.232 & 0.057 & 0.264 & 0.626 & $\$ 761.82$ \\
\hline Grade 1 Large & 8 & 0.330 & 0.074 & 0.164 & 0.041 & 0.140 & 0.057 & 0.194 & 0.479 & $\$ 862.36$ \\
\hline
\end{tabular}

\section{Cherry}

Table 20. Lumber Yields and Overrun for Revised Cherry Batches

\begin{tabular}{|c|c|c|c|c|c|c|c|c|c|}
\hline \multirow[b]{2}{*}{ Batch } & \multirow[b]{2}{*}{$\mathrm{n}$} & \multicolumn{6}{|c|}{ NHLA Lumber Grades } & \multirow[b]{2}{*}{ Overrun } & \multirow[b]{2}{*}{$\begin{array}{c}\text { Break } \\
\text { Even }\end{array}$} \\
\hline & & $\begin{array}{l}\text { FAS- } \\
\text { Sap }\end{array}$ & $\begin{array}{l}\text { FAS- } \\
\text { Red }\end{array}$ & $1 C$ & $2 \mathrm{C}$ & $3 C$ & CANT & & \\
\hline Grade 1 Large & 20 & 0.380 & 0.032 & 0.269 & 0.097 & 0.036 & 0.186 & 0.441 & $\$ 529.68$ \\
\hline Grade 2 Small & 10 & 0.006 & 0.187 & 0.355 & 0.198 & 0.032 & 0.222 & 0.427 & $\$ 328.93$ \\
\hline
\end{tabular}

\section{Individual Log Breakeven Analysis, AHMI/AHC Method}

This breakeven analysis used the results from the AHMI/AHC Method of conducting an individual log study. Since the cooperating mills grading table (Figure 8) does not distinguish between species, all the logs of the same diameter/clear face combination were aggregated, according to the following table layout (similar to Figure 8 , but with Grade 1 Small Diameter separated by clear faces). For instance, all $\geq 17$ inch logs with 4 clear faces (total of 62 logs) were combined and totaled across all species. The number of sample logs in each scaling diameter/clear face combination is provided in Table 21 below.

\begin{tabular}{|c|c|c|c|}
\hline \multirow{2}{*}{ Scaling } & \multicolumn{3}{|c|}{ Clear Faces } \\
\cline { 2 - 4 } Diameter & 4 & 3 & 2 \\
\hline
\end{tabular}




\begin{tabular}{|c|c|c|c|}
\hline$\geq 17 "$ & 62 & 33 & 20 \\
\hline $16 "$ & 18 & 19 & 4 \\
\hline $15 "$ & 20 & 16 & 4 \\
\hline $14 "$ & 25 & 16 & 21 \\
\hline $13 "$ & 28 & 25 & 13 \\
\hline $12 "$ & 9 & 13 & 8 \\
\hline
\end{tabular}

Table 21. The number of logs from the AHMI/AHC Method of individual log analysis in each cell of the scaling diameter/clear face matrix, as defined by the cooperating mills grading and scaling protocols.

In this analysis, for any cell containing fewer than 8 logs, no breakeven price was calculated. For long term purposes of determining breakeven pricing, a much greater number of logs need to be processed. However, for the purposes of this study, the sample sizes in the remaining cells were deemed sufficient for illustrating the differences between batch and individual log studies.

In order to illustrate the breakeven comparison of batch and individual log methods, breakeven pricing will be based on Red Oak, so that product pricing and sawing costs will be specific to Red Oak. The lumber grade yields and overrun will be based on the aggregated data. Since lumber grade yields and overrun are not species specific, it is not necessary to perform the analysis on the other species, as the only difference would be product pricing and sawing cost, which would make the analyses proportional. Table 22 provides lumber grade yields and overrun by scaling diameter and clear faces. 
Table 22. Lumber Grade Yields and Overrun for the Individual Log Analysis.

\begin{tabular}{|c|c|c|c|c|c|c|c|c|c|}
\hline \multirow{2}{*}{$\begin{array}{l}\text { Scaling } \\
\text { Diameter }\end{array}$} & \multirow{2}{*}{$\begin{array}{l}\text { Clear } \\
\text { Faces }\end{array}$} & \multicolumn{7}{|c|}{ NHLA Lumber Grade Yields } & \multirow{2}{*}{ Overrun } \\
\hline & & FAS & $1 \mathrm{~F}$ & $1 \mathrm{C}$ & $2 \mathrm{~A}$ & $3 \mathrm{~A}$ & $3 B$ & CANT & \\
\hline & & \multicolumn{8}{|c|}{ (in decimal format) } \\
\hline$\geq 17 "$ & 4 & 0.4235 & 0.1429 & 0.1941 & 0.0746 & 0.0210 & 0.0010 & 0.1429 & 0.2194 \\
\hline $16 "$ & 4 & 0.3585 & 1507 & 0.1863 & 0.0811 & 0.0128 & 0.0056 & 0.2050 & 0.2930 \\
\hline $15 "$ & 4 & 0.3627 & 0.1326 & 0.1664 & 0.0783 & 0.0169 & 0.0014 & 0.2418 & 0.4468 \\
\hline 14" & 4 & 0.2569 & 1297 & 0.2007 & 0.1045 & 0.0359 & 0.0017 & 0.2705 & 0.5179 \\
\hline 13" & 4 & 0.1586 & 0.1612 & 0.1728 & 0.1500 & 0.0379 & 0.0065 & 0.3129 & 0.5761 \\
\hline 12" & 4 & 0.1954 & 0.0986 & 0.1799 & 0.1683 & 0.0077 & 0.0135 & 0.3366 & 0.6361 \\
\hline$\geq 17^{\prime \prime}$ & 3 & 0.2609 & 0.1600 & 0.2333 & 0.1389 & 0.0420 & 0.0063 & 0.1584 & 0.2752 \\
\hline 16" & 3 & 0.1889 & 0.1582 & 0.2539 & 0.1541 & 0.0495 & 0.0098 & 0.1856 & 0.3993 \\
\hline $15 "$ & 3 & 0.1801 & 0.0829 & 0.2397 & 0.1878 & 0.0334 & 0.0447 & 0.2314 & 0.3320 \\
\hline 14" & 3 & 0.1482 & 0.1589 & 0.2522 & 0.1255 & 0.0359 & 0.0132 & 0.2661 & 0.4392 \\
\hline $13 "$ & 3 & 0.0881 & 0.1095 & 0.2556 & 0.1899 & 0.0604 & 0.0271 & 0.2694 & 0.5575 \\
\hline 12" & 3 & 0.0627 & 0.0901 & 0.2531 & 0.2075 & 0.0479 & 0.0160 & 0.3227 & 0.7096 \\
\hline$\geq 17^{\prime \prime}$ & 2 & 0.1231 & 0.1311 & 0.3301 & 0.2339 & 0.0433 & 0.0049 & 0.1335 & 0.2120 \\
\hline $16 "$ & 2 & -- & -- & --- & -- & -- & -- & --- & -- \\
\hline $15 "$ & 2 & -- & -- & -- & --- & -- & -- & -- & --- \\
\hline $14 "$ & 2 & 0.0819 & 0.0881 & 0.3528 & 0.1987 & 0.0369 & 0.0225 & 0.2192 & 0.0470 \\
\hline 13" & 2 & 0.0332 & 0.0629 & 0.3378 & 0.2462 & 0.0288 & 0.0108 & 0.2803 & 0.6060 \\
\hline 12" & 2 & 0.0220 & 0.1040 & 0.1780 & 0.2460 & 0.0500 & 0.0320 & 0.3680 & 0.6502 \\
\hline \multicolumn{2}{|c|}{$\begin{array}{l}\text { Lumber } \\
\text { Prices (\$/mbf) }\end{array}$} & 740 & 740 & 585 & 570 & 505 & 282 & 470 & \\
\hline \multicolumn{2}{|c|}{$\begin{array}{l}\text { Sawing Cost } \\
\text { (\$/mbf) }\end{array}$} & 30 & & & & & & & \\
\hline
\end{tabular}

The breakeven pricing, by scaling diameter and clear faces, is presented in Figure 27. For comparison purposes of batch versus individual methods, Figure 26 represents the batch breakeven results presented in Table 9 in the form of the cooperating mill's grading matrix (similar to Figure 8 , but without the cells not included in the batch studies). 


\begin{tabular}{|c|c|c|c|}
\hline Scaling & \multicolumn{3}{|c|}{ Clear Faces } \\
\hline Diameter & 4 & 3 & 2 \\
\hline$\geq 17 "$ & $\$ 428.94$ & $\$ 383.66$ & $\$ 353.83$ \\
\hline $16 "$ & & & \\
\hline $15 "$ & \multirow{4}{*}{\multicolumn{2}{|c|}{$\$ 412.89$}} & \multirow{4}{*}{$\$ 372.50$} \\
\hline $14 "$ & & & \\
\hline $13 "$ & & & \\
\hline $12 "$ & & & \\
\hline
\end{tabular}

Figure 26. Breakeven Prices for the Red Oak Batches

\begin{tabular}{|c|c|c|c|}
\hline \multirow{2}{*}{ Scaling } & \multicolumn{3}{|c|}{ Clear Faces } \\
\cline { 2 - 4 } Diameter| & 4 & 3 & 2 \\
\hline$\geq 17 "$ & $\$ 431.01$ & $\$ 414.26$ & $\$ 364.54$ \\
\hline $16 "$ & $\$ 430.24$ & $\$ 431.57$ & --- \\
\hline $1{ }^{\prime \prime}$ & $\$ 479.20$ & $\$ 373.38$ & --- \\
\hline $14 ”$ & $\$ 469.13$ & $\$ 422.30$ & $\$ 402.05$ \\
\hline $13 "$ & $\$ 459.50$ & $\$ 418.85$ & $\$ 415.33$ \\
\hline $12 "$ & $\$ 465.99$ & $\$ 444.47$ & $\$ 404.33$ \\
\hline
\end{tabular}

Figure 27. Breakeven Prices by Scaling Diameter and Clear Faces based on the AHMI/AHC Method of Individual Log Studies. 


\section{Discussion}

Accurate pricing of purchased logs is vital to ensure a profitable sawmill operation. An objective of this study was to compare results between two approaches, the batch mill study and the individual log study, with the intent of determining which method provides more reliable results for estimating log breakeven pricing. Based on reviewed literature, it became apparent that batch studies must be very carefully assembled to ensure accurate and reliable results. An improperly conducted batch study does not provide results with the accuracy necessary to make key decisions in setting log prices. This section will further explore the factors that can negatively impact the accuracy of breakeven prices as determined by a batch log study.

\section{Variation Within Batches}

The Cochran-Mantel-Haenszel analysis tested to determine if log diameter frequencies were different between batches of the same grade designation (e.g., Prime grade batches of which there were three). This was done for each log grade. Results from the Cochran-Mantel-Haenszel analysis suggested that the frequency distributions/batch compositions were statistically different for each log grade except the Grade 1 Large diameter batches.

In general, lumber grade yields and overrun are different within each batch. Of the 15 comparisons of lumber grade yields over the five different batch grade designations (One Face and Better, 1 Common, and 2 Common and below plus cants), 9 of 15 grade yields showed statistical significance. Similarly, four out of five of the batch designations showed overrun to be statistically significant. Therefore, when 
batches of the same log grade have different diameter frequencies, batch breakeven prices can vary substantially, since pricing is directly dependent on lumber grade yields and overrun. This poses a major issue when relying on batch mill studies to provide accurate insight into profitability.

A useful illustration of this is in the Yellow-poplar Grade 1 Small batches. Two batch studies were conducted, with each providing different breakeven pricing. The November batch had a calculated breakeven price of $\$ 449.41$ per MBF, while the January batch had a calculated breakeven price of $\$ 467.49$ per MBF.

The average diameter of the November batch was 13.84 inches, while the average diameter of the January batch was 14.32 inches (there were six more 15 inch logs and six fewer 13 inch logs in the January batch). The different mix of diameters in these batches led to statistically different One Face and Better lumber yields between the two batches, with the November batch having $30.4 \%$ One Face and better and the January batch having $40.0 \%$ One Face and Better lumber yield.

Overrun was not statistically different between the two batches, although there was a rather large overrun difference. The November batch had an overrun of $47.2 \%$, while the January batch had an overrun of $37.8 \%$.

In the case of these two yellow-poplar batches, the batch composition led to statistically significant and actual differences that ultimately contributed to a difference in the breakeven price of $\$ 18.08$ per MBF between the batches.

While a comparison of two batches of the same species and log grade provides a useful illustration, the effect of diameter frequency differences on lumber yields and 
overrun occurs in all batches. For any of the batches, if the log diameter frequencies were different, the calculated breakeven price would undoubtedly change. This is a major issue with the batch study system; batch composition must remain consistent across batches to achieve consistency in the results.

\section{Impact of Rolling/Not Rolling Logs during Scaling}

Rolling logs during the scaling and grading process is critical to ensure accurate log grading and consistent application of the scaling deductions for defects. All logs were rolled as part of the individual log study process, so that all four faces of every log could be observed. The participating sawmill did not roll logs during the grading and scaling process, so a maximum of three faces were observed by the log scalers (although the bunching of logs closely together, which was common, realistically allows observation of one face). The decision not to roll the logs in the yard affected accuracy during log grading and scaling as shown by the Kappa agreement statistic for all 16 batches. It also affected log scaling results, as shown in the overrun comparisons between the two methodologies.

The Kappa agreement statistic found indicated that 12 of 16 batches $(75 \%)$ had moderate or substantial agreement (Kappa of 0.41 to 0.80 ) in diameter measurements between the batch study and individual log study methods. Overall, diameter measurements were relatively similar between the two methods. In the case of scaling diameters, not rolling the logs had much less of an impact on diameter measurement than with clear face determination as discussed below. 
The Kappa agreement statistic found that only 4 of 16 batches (25\%) had moderate or substantial agreement in log grades. Eight out of the 16 batches (50\%), had only slight agreement (Kappa less than 0.21) suggesting that log grading at the participating sawmill is not consistent, as the log inspectors only see three faces of the log, at most. Rolling the logs, or at least providing room between each log during scaling and grading, would increase accuracy in log grading and improve the effectiveness of the batch mill study approach.

Even though diameter measurements showed a high amount of agreement between the two methods, there were some statistically significant differences in overrun between the batch mill study approach and the individual log method. Tables 5 and 6 provide these comparisons. Large differences in overrun were observed between the two methods, although only two of the comparisons were statistically significant. The largest difference in overrun between the two methods was for the Soft Maple Grade 1 Large diameter batch, with an overrun difference of $13.4 \%$, though this difference was not statistically significant. The two statistically significant overrun results were Yellowpoplar Grade 1 small January and Yellow-poplar Grade 2 large with 10.9 and 11.9\%, respectively.

From a breakeven pricing perspective, the difference in overrun resulting from not turning the logs can be significant, as illustrated by the Soft Maple Grade 1 Large Diameter batch. The $13.4 \%$ difference in overrun resulted in a $\$ 812.98$ batch breakeven price (Table 11). The individual log approach in turning the logs resulted in a breakeven price of $\$ 898.02$ (Table 15 ), a difference of $\$ 78.04$. While the result is favorable to the mill from a financial perspective, the batch method is not accurately reflecting the value 
of the batch. It is quite likely that the mill is not capturing the volume of logs that it could as a result of offering a significantly lower price in the marketplace for logs fitting this batch description. A similar outcome was observed in breakeven pricing when comparing the batch results to the revised $\mathrm{AHMI} / \mathrm{AHC}$ batches, where only those logs fitting the batch criteria were analyzed. The Soft Maple batch cited above resulted in a revised AHMI/AHC breakeven price of $\$ 862.36$, a $\$ 49.48$ difference from the mill batch.

This indicates that not rolling the logs during the batch study can lead to differences in overrun. The Kappa agreement statistic indicated relatively high agreement in diameter measurements between the two methods. Therefore, diameter measurements were probably not the source for the large observed differences in overrun.

However, scaling defects that would have reduced log volume were not routinely observed and properly deducted primarily because the logs were not rolled, which led to missed defects and higher log scales. This higher log scale then produced smaller overrun compared to the individual log study approach.

\section{Potential Financial Impact of Improper Batch Results}

The breakeven analysis section is extended in this section to further focus on the differences between the batch study and individual log study methods and the potential impact on sawmill profitability.

For example, the Red Oak Grade 1 Large diameter batch had a breakeven price of $\$ 383.66$. Figure 13 on page 37 provides the grading and scaling results for both the 
batch and individual log study. According to the individual log grading and scaling results, where logs were rolled so that all four faces were visible, six Prime grade logs were included in the batch, five Grade 2 logs were included, and three Grade 3 logs were included. In total, 14 improperly graded logs were included in the batch. The inclusion of these logs obviously affected the breakeven price as determined by the batch study.

The individual log study found that Red Oak Grade 1 Large diameter logs had a breakeven price of $\$ 431.57$ per MBF for 16 -inch logs (Figure 27 ), and $\$ 414.26$ per MBF for 17 -inch and larger logs (Figure 27). According to the individual log study, the average breakeven price of Red Oak Grade 1 Large diameter logs was $\$ 422.92$. This leads to a difference of $\$ 39.26$ per MBF between the two methods.

If a sawmill were to buy and saw 200MBF of Red Oak Grade 1 Large diameter logs according to the batch study results, they would pay $\$ 76,732$ for these logs. Buying the same logs, using the average price from the individual log study, would lead to a total log cost of $\$ 84,584$. In a competitive market where log availability is an issue, the use of the batch results in this instance could reduce log availability and cause log supply issues, due to undervaluing the logs included in this batch definition.

From another perspective, two batch studies were completed in the Yellowpoplar Grade 1 Small diameter log grade. The November batch had a breakeven price of $\$ 449.41$ per MBF, while the January batch had a breakeven price of $\$ 467.49$ per MBF. This amounts to a difference of $\$ 18.08$ per MBF. If a sawmill annually bought and sawed $1000 \mathrm{MBF}$ of logs in this grade, they would pay an extra $\$ 18,080$ by using the 
January batch breakeven price. Of course, this does not take into account any differences in breakeven pricing resulting from the AHMI/AHC individual log method.

In a very competitive hardwood market with small profit margins, accurate and reliable log pricing information is critical. Although $\$ 18.08$ per MBF may seem like a small difference, when compounded through a year of sawmill production, it amounts to a large sum of money. The small difference in log purchase price could very easily be the difference between a profitable or unprofitable year.

\section{Downfalls of the Batch Study Method and Suggestions for Improvement}

The batch mill study approach has several problems related to the collected data when trying to accurately price logs. In combination, these factors work to limit the reliability and accuracy of the batch mill study approach as it relates to determining breakeven pricing of logs. Problems with the batch study approach include:

- The lack of log-specific data: In the batch study approach, there is no way to track lumber yields by log. At the end of the batch study, the main results are lumber yields by grade and overrun. This data is gathered for the entire batch, not for each log. This is a major issue when batches have a wide range of diameters and clear faces.

- Limited statistical options: The batch study approach provides only one result at the conclusion of the analysis. As such, a batch study is essentially one observation. Even though the batches contained 20 or 25 logs each, the results provide one observation into lumber grade yield percentages and 
overrun. No statistical analyses, such as mean, standard deviation and confidence intervals, can be computed for a single observation.

- Breakeven price is heavily influenced by log diameter frequencies: Since each batch generally contains a range of diameters rather than one single diameter, the breakeven price is weighted towards the log diameter occurring most frequently in the developed batch. This skews the breakeven price and minimizes the pricing impact of log diameters that were less frequent in the batch.

- Large amounts of variability within batches of the same log grade: When incorrectly graded logs are included in a batch, even though they should not be in that batch, breakeven price is affected by the presence of those logs. An example of this is in the November Grade 1 small diameter Yellow-poplar batch. The original batch had a breakeven price of $\$ 449.41$ per MBF. After two logs were removed that did not belong in the batch, the breakeven price was $\$ 467.01$ per MBF, a difference of $\$ 17.60$ per MBF.

- Another example of this is in the Grade 2 large diameter Yellow-poplar batch. The original batch had a breakeven price of $\$ 320.94$ per MBF. There were 14 logs in this batch that were incorrectly graded and did not belong in the batch. After these logs were removed, the revised batch had a breakeven price of $\$ 227.31$, a difference of $\$ 93.63$ per MBF. These two examples illustrate just how much the batch breakeven price can be influenced by batch composition. When a batch contains a wide range of log grades or diameters, the results are highly unreliable. 
If a mill is constrained to conducting only batch studies, there are several ways to improve the batch study approach to improve accuracy and reliability.

- Each batch should be composed of logs of the same grade, with a very narrow diameter range. An ideal batch is one that is focused in one cell of the grading table. For example, a well-defined batch would be a 12", 4 clear face batch. A batch with a wide range of diameters or clear faces does not produce reliable, accurate results.

- Ensure logs that are to be included in a batch study are correctly scaled and graded. Ideally, logs should be rolled so that all four faces of every log can be observed.

- More than one batch study should be conducted for each cell in the grading table. This will allow statistics, specifically the means and standard deviations to be calculated, further verifying the reliability of the batch study results. However, conducting enough batch studies to develop an adequate number of observations may be too expensive for a mill to take on. The alternative is to take the time to collect individual log data so that each study contributes multiple observations to the mill's individual log dataset.

\section{Interaction of Lumber Yields and Overrun and their Combined effect on Breakeven Price}

There is a preconceived notion in the industry that larger logs are more valuable than smaller logs. As the individual log breakeven analyses show, this is not necessarily true in all instances. Figure 27 shows that a 12" DIB Red Oak log with four clear faces 
has a higher breakeven cost $(\$ 465.99$ per MBF) than do the $\geq 17$ " Prime grade logs (\$431.01 per MBF)

When determining a breakeven price for a log, it is important to understand the interaction between lumber grade yields and overrun. Overrun has a large impact on the breakeven price of logs, particularly when using the Doyle scale. Larger logs typically have better yields of high-quality lumber, in this case One Face and better, than do smaller logs with the same number of clear faces. However, higher yields of One Face and better lumber in larger logs does not always equate to higher breakeven costs, because larger logs typically produce less overrun than smaller diameter logs

In the above example, the $\geq 17$ " DIB Red Oak logs have a One Face and better lumber yield of $56.64 \%$, with an overrun of $21.94 \%$. The 12 " DIB Red Oak logs have a One Face and better lumber yield of $29.4 \%$, with an overrun of $63.61 \%$. The larger logs have a considerably higher yield of One Face and better lumber, but the larger overrun in the 12" DIB logs more than makes up for the lower yield of One Face and better lumber.

Tables 2, 3, and 4 show that lumber grade yields were not statistically different between the batch and individual log study methods. Tables $5,6,7$, and 8 showed very few statistically significant differences in overrun between the batch and individual log study approaches. Even though these differences were not significant, there were substantial differences in the calculated breakeven price between the two methods. From a mill management perspective, statistical significance of lumber yields and overruns may not be important, but the breakeven price differences between the two methods are critically important for maintaining profitability. 


\section{Conclusions}

Based on this study, the batch mill study approach is not a reliable way to set log pricing, especially using the methods detailed here. The individual log study is a more reliable way to accurately gather lumber yield and overrun information for logs, when calculating log breakeven pricing. With some of the recommended improvements in data collection, the batch mill study has the potential to improve reliability and accuracy but needs further study to confirm this.

This study suggests that the accuracy of a batch study can be significantly compromised if the logs in the batch are a mix of sizes and grades. The best outcome from a batch study would be to specify a single grade and a single diameter for all logs included in the batch. Since individual logs are not tracked through the mill, as they are in an individual log study, batches of logs must be constructed that tie lumber yields to very specific log size and grade parameters.

If a sawmill conducts batch mill studies, considerable time and effort should go into the careful construction of each batch. The batch should be of a very narrow diameter range, preferably just one diameter and clear face combination. All log diameters should be accurately measured, and all log faces observed to ensure that each log in the batch truly belongs in the batch.

When using a clear face log grading system, log grades cannot be accurately assigned without rolling the logs and observing all parts of the log. At an absolute minimum, logs should be spaced apart so that log inspectors can observe at least three 
faces. When logs are stacked tightly together during scaling, the log inspectors cannot accurately assess the number of clear faces.

Further study is needed to determine if the batch study method can provide more accurate and reliable results when the batch is composed of logs of a single log grade and diameter. Based on the results from this study, batch study data can lead to log purchases at costs well above their actual breakeven value. Hardwood sawmills would be better served to make the effort to use individual log studies to improve mill profitability. 


\section{Literature Cited}

American Hardwood Export Council. 2008. The Illustrated Guide to American Hardwood Lumber Grades. 21pp.

Appalachian Hardwood Manufacturers Inc. 2019. Guidelines for the Scaling and Grading of Hardwood Logs, $1^{\text {st }}$ Edition. 14pp.

Avery, T. E., \& Burkhart, H. E. 2002. Forest measurements. Boston: McGraw-Hill. 456pp.

Benson, A.O., and A.C. Wollin. 1938. Grading Hardwood Logs. Project L-260-2, Working Plan. USDA Forest Service, For. Prod. Lab. 22pp.

Burry, H. W., G. M. Bliss, and K. F. Burns. 1977. Hardwood Lumber Recovery and Sawmill Efficiency in New York. State University of New York (SUNY), Applied Forestry Institute, AFRI Research Report No. 33. 24pp.

Calvert, W. W. 1956. Grading Hardwood Logs for Factory Lumber. Forest Products Laboratories of Canada, Ottawa Laboratory. 4pp. 
Gove, William G. 1984. Processing and Yield Studies in Vermont's Sawmill Industry. Vermont Department of Forests, Parks, and Recreation. 150pp.

Govett, Robert; R. Dramm; S. Bowe; and; T. Mace. 2006. GRADEYIELD- Lumber Grade and Yield Studies for Analysis of Sawmill Profit-Potential. University of Wisconsin, Stevens Point. 12pp.

Graves, D.H.. (1986). A Landowners Guide: Measuring Farm Timber. Retrieved May 10, 2020, from http://www2.ca.uky.edu/agcomm/pubs/for/for9/for9.htm

Hanks, L.F. 1973. Green lumber grade yields for sub-factory class hardwood logs. USDA Forest Service Research Paper NE-256. 8pp.

Hanks, L. F., G. L. Gammon, R.L. Brisbin, and E.D. Rast. 1980. Hardwood Log Grades and Lumber Grade Yields for Factory Lumber Logs. USDA Forest Service, Northeastern Forest Experiment Station, Broomall, PA. USDA FS Research Paper NE-468. 92pp.

Hassler, C. C., L.E. Osborn, S.T. Grushecky, and J. F. McNeel, Hardwood Log Grading in the United States-Part II: United States Forest Service Log Grades and the Hardwood Industry. Forest Prod. J. 69(2):124-130. 
Herrick, A. M. 1946. Grade yields and overrun from Indiana hardwood sawlogs. Purdue University Agricultural Experiment Station, Agr. Exp. Sta. Bul. 516. 60pp.

JMP®, Version Pro 14.0, SAS Institute Inc., Cary, NC, Copyright @2015; SAS $®$, Version 9.4, SAS Institute Inc., Cary, NC, Copyright @2002-2012

Landis JR, Koch GG. 1977. The measurement of observer agreement for categorical data. Biometrics 33:159-74.

Mayer, Robert, Wiedenbeck, Jan. 2005. Continuous sawmill studies: protocols, practices, and profits. Gen. Tech. Rep. NE-334. Newtown Square, PA: U.S. Department of Agriculture, Forest Service, Northeastern Research Station. 32pp.

National Hardwood Lumber Association. 2019. Rules for the measurement and inspection of hardwood and cypress. 101pp.

Rast, E.D., D. L. Sonderman, and G. L. Gammon. 1973. A Guide to Hardwood Log Grading. USDA Forest Service, Northeastern Forest Experiment Station, Upper Darby, PA. Gen. Tech. Rep. NE-1. 32pp. 
Schroeder, J.G. and L.F. Hanks. 1967. Lumber Grade Yields for Factory-Grade Northern Red Oak Sawlogs. USDA Forest Service, Northeastern Forest Experiment Station, Upper Darby, PA. Research Note NE-65. 13pp.

Schroeder, J.G. 1968. Lumber grade yields for sub-factory class red oak logs. U.S. Forest Service, Northeastern Forest Experiment Station, Upper Darby, PA. Research Paper NE-114. 15pp.

Steele, Philip H. 1984. Factors determining lumber recovery in sawmilling. Gen. Tech. Rep. FPL-39. Madison, WI: U.S. Department of Agriculture, Forest Service, Forest Products Laboratory. 8pp.

Stokes, M. E., C. S. Davis and G. G. Koch. 2012. Categorical Data Analysis using SAS $®$, Third Edition. Cary, NC: SAS Institute Inc.

Vaughan, C.L., A.C. Wollin, K.A. McDonald, and E.H. Bulgrin. 1966. Hardwood log grades for standard lumber. U.S. Forest Service, Forest Products Laboratory, Research Paper FPL 63. 54pp.

Vierra, A.J. and, J.M. Garrett. 2005. Understanding Interobserver Agreement: The Kappa Statistic. Family Medicine 2005; 37(5): 360-363. 
Wollin, A. C. and C. L. Vaughan. 1949. Hardwood Log Grades and Standard Lumber Proposals and Results. USDA Forest Service, Forest Products Lab, D1737. 15pp. 


\section{Appendix}

Doyle Log rule used for log grading and scaling

\begin{tabular}{|c|c|c|c|c|c|c|c|c|c|c|c|}
\hline \multicolumn{12}{|c|}{ Doyle Log Rule } \\
\hline \multirow{2}{*}{\begin{tabular}{|c|} 
Scaling \\
Diameter (in)
\end{tabular}} & \multicolumn{11}{|c|}{ Log Length (ft) } \\
\hline & 6 & 7 & 8 & 9 & 10 & 11 & 12 & 13 & 14 & 15 & 16 \\
\hline 8 & 6 & 7 & 8 & 9 & 10 & 11 & 12 & 13 & 14 & 15 & 16 \\
\hline 9 & 9 & 11 & 13 & 14 & 16 & 17 & 19 & 20 & 22 & 23 & 25 \\
\hline 10 & 14 & 16 & 18 & 20 & 23 & 25 & 27 & 29 & 32 & 34 & 36 \\
\hline 11 & 18 & 21 & 25 & 28 & 31 & 34 & 37 & 40 & 43 & 46 & 49 \\
\hline 12 & 24 & 28 & 32 & 36 & 40 & 44 & 48 & 52 & 56 & 60 & 64 \\
\hline 13 & 30 & 35 & 41 & 46 & 50 & 56 & 61 & 66 & 71 & 76 & 81 \\
\hline 14 & 38 & 44 & 50 & 56 & 62 & 69 & 75 & 81 & 88 & 94 & 100 \\
\hline 15 & 45 & 53 & 61 & 68 & 75 & 83 & 91 & 98 & 106 & 113 & 121 \\
\hline 16 & 54 & 63 & 72 & 81 & 90 & 99 & 108 & 117 & 126 & 135 & 144 \\
\hline 17 & 63 & 74 & 85 & 95 & 106 & 116 & 127 & 137 & 148 & 158 & 169 \\
\hline 18 & 74 & 86 & 98 & 110 & 122 & 135 & 147 & 159 & 171 & 184 & 196 \\
\hline 19 & 84 & 98 & 113 & 127 & 141 & 155 & 169 & 183 & 197 & 211 & 225 \\
\hline 20 & 96 & 112 & 128 & 144 & 160 & 176 & 192 & 208 & 224 & 240 & 256 \\
\hline 21 & 108 & 126 & 145 & 163 & 181 & 199 & 217 & 235 & 253 & 271 & 289 \\
\hline 22 & 122 & 142 & 162 & 182 & 202 & 223 & 243 & 263 & 283 & 304 & 324 \\
\hline 23 & 135 & 158 & 181 & 203 & 226 & 248 & 271 & 293 & 316 & 338 & 361 \\
\hline 24 & 150 & 175 & 200 & 225 & 250 & 275 & 300 & 325 & 350 & 375 & 400 \\
\hline 25 & 165 & 193 & 221 & 248 & 276 & 303 & 331 & 358 & 386 & 413 & 441 \\
\hline 26 & 182 & 212 & 242 & 272 & 302 & 333 & 363 & 393 & 423 & 454 & 484 \\
\hline 27 & 198 & 231 & 265 & 298 & 330 & 364 & 397 & 430 & 463 & 496 & 530 \\
\hline 28 & 216 & 252 & 288 & 324 & 360 & 396 & 432 & 468 & 504 & 540 & 576 \\
\hline 29 & 234 & 273 & 313 & 352 & 391 & 430 & 469 & 508 & 547 & 586 & 625 \\
\hline 30 & 254 & 296 & 338 & 380 & 422 & 465 & 507 & 549 & 591 & 634 & 676 \\
\hline
\end{tabular}

